\title{
Synthesis and characterization of $\mathrm{NaNiF}_{3} \cdot 3 \mathrm{H}_{2} \mathrm{O}$ : an unusual ordered variant of the $\mathrm{ReO}_{3}$ type
}

Elena C. Gonzalo ${ }^{1,}$, María Luisa Sanjuán ${ }^{2}$, Markus Hoelzel ${ }^{3}$, M. Teresa Azcondo ${ }^{1}$, Ulises Amador ${ }^{1}$, Isabel Sobrados ${ }^{4}$, Jesús Sanz ${ }^{4}$, Flaviano GarcíaAlvarado ${ }^{1}$ and Alois Kuhn ${ }^{1, *}$

${ }^{1}$ Universidad CEU San Pablo. Facultad de Farmacia, Departamento de Química y Bioquímica, Urbanización Montepríncipe, 28668 Boadilla del Monte, Madrid, Spain.

† Present address: CIC Energigune, Parque Tecnológico de Álava, 01510 Miñano, Spain

${ }^{2}$ Instituto de Ciencia de Materiales de Aragón (Universidad de Zaragoza-CSIC), Facultad de Ciencias, 50009 Zaragoza, Spain

3 Forschungsneutronenquelle Heinz Maier-Leibnitz (FRM II), D-85747 Garching, Germany

${ }^{4}$ Instituto de Ciencia de Materiales de Madrid, CSIC, Spain 


\begin{abstract}
A new hydrated sodium nickel fluoride with nominal composition $\mathrm{NaNiF}_{3} \cdot 3 \mathrm{H}_{2} \mathrm{O}$ was synthesized using an aqueous solution route. Its structure has been solved by means of $a b$ initio methods from powder X-ray diffraction and neutron diffraction data. $\mathrm{NaNiF}_{3} \cdot 3 \mathrm{H}_{2} \mathrm{O}$ crystallizes in the cubic crystal system, space group $P n-3$ with $a=$ 7.91968(4) $\AA$. The framework, derived from the $\mathrm{ReO}_{3}$ structure type, is built up by $\mathrm{NaX}_{6}$ and $\mathrm{NiX}_{6}(\mathrm{X}=\mathrm{O}, \mathrm{F})$ corner-shared octahedra, in which $\mathrm{F}$ and $\mathrm{O}$ atoms are randomly distributed on a single anion site. The $2 a \times 2 a \times 2 a$ superstructure arises from the strict alternate 3D-link-up of $\mathrm{NaX}_{6}$ and $\mathrm{NiX}_{6}$ octahedra together with the simultaneous tilts of the octahedra from the cube axis $\left(\varphi=31.1^{\circ}\right)$, with a significant participation of hydrogen bonding. $\mathrm{NaNiF}_{3} \cdot 3 \mathrm{H}_{2} \mathrm{O}$ corresponds to a fully cation ordered variant of the $\operatorname{In}(\mathrm{OH})_{3}$ structure, easily recognizable when formulated as $\mathrm{NaNi}(\mathrm{XH})_{6}$ $(\mathrm{X}=\mathrm{O}, \mathrm{F})$. It constitutes one of the rare examples for the $a^{+} a^{+} a^{+}$tilting scheme with $1: 1$ cation ordering in perovskite-related compounds. The Curie-like magnetic behavior well reflects the isolated paramagnetic $\mathrm{Ni}^{2+}$ centers without worth mentioning interactions. While X-ray and neutron diffraction data evidence $\mathrm{Na} / \mathrm{Ni}$ order in combination to $\mathrm{O} / \mathrm{F}$ disorder as a main feature of this fluoride, results from Raman and MAS-NMR spectroscopies support the existence of specific anion arrangements in isolated square windows identified in structural refinements. In particular, formation of water molecules derives from unfavorable $\mathrm{FH}$ bond formation.
\end{abstract}




\section{Introduction}

$\mathrm{AMF}_{3}\left(\mathrm{~A}=\mathrm{Na}, \mathrm{K}, \mathrm{NH}_{4}\right)$ fluorides have been investigated since the $60{ }^{\prime}$ s. $^{1,2}$ Sodium fluoroperovskites $\mathrm{NaMF}_{3}$ are known for a number of divalent transition metals such as $\mathrm{Mg}, \mathrm{Mn}, \mathrm{Fe}, \mathrm{Co}, \mathrm{Ni}, \mathrm{Cu}$ or $\mathrm{Zn}$. These fluorides are usually synthesized by the ceramic route using stoichiometric mixtures of the binary fluorides $\mathrm{NaF}$ and $\mathrm{MF}_{2}$ which were typically heated at temperatures ranging from 700 and $900^{\circ} \mathrm{C}$ in welded gold or platinum ampoules. ${ }^{3-6} \mathrm{NaNiF}_{3}$ was first prepared by Babel et al. ${ }^{7}$, followed by reports on other isostructural $\mathrm{NaMF}_{3}$ perovskites. ${ }^{8}$ They crystallize in the orthorhombic system, space group (SG) Pbnm. The ideal cubic perovskite structure is only found for $\mathrm{K}$ fluoroperovskites, while in $\mathrm{Na}$ fluoroperovskites the symmetry is lowered to orthorhombic because of tilting of the anion octahedra, displacement of the alkaline metal from the center of the cuboctahedron or distortion of the $\mathrm{MF}_{6}$ octahedron. ${ }^{9}$

$\mathrm{NaMF}_{3}$ sodium metal fluorides are interesting as prospective electrode materials for lithium or sodium batteries. Recently Gocheva et al. ${ }^{10}$ reported on the electrochemical properties of $\mathrm{NaMF}_{3}(\mathrm{M}=\mathrm{Fe}, \mathrm{Mn}, \mathrm{Ni})$ obtained by mechanochemical synthesis as positive electrodes for rechargeable sodium batteries. For $\mathrm{NaFeF}_{3}$ a modified synthesis procedure has allowed the discharge capacity of sodium batteries to be increased from $120 \mathrm{mAh} \mathrm{g}^{-1}$ up to high $197 \mathrm{mAh} \mathrm{g}^{-111,12}$, confirming the interest of transition metal fluorides as new electrode materials. In this connection we reported on the facile low cost synthesis of $\mathrm{Na}$ fluoroperovskites with formula $\mathrm{NaMF}_{3}(\mathrm{M}=\mathrm{Mg}$, $\mathrm{Mn}, \mathrm{Fe}, \mathrm{Co}, \mathrm{Zn})$ by precipitation from aqueous solution at room temperature. ${ }^{13}$ However, for $\mathrm{M}=\mathrm{Ni}$ the precipitation reaction did not lead to the desired $\mathrm{NaNiF}_{3}$ perovskite phase. In this paper we have further investigated the nature of the Na-Ni-F compound formed by precipitation reaction using the aqueous solution route. As we shall see, chemical analysis and TGA have allowed for determining accurately the 
chemical formula of a new hydrated sodium nickel fluoride, and its crystal structure has been unveiled by powder X-ray and neutron diffraction. Complementary electron diffraction was used as appropriate tool for space group assignment. The structural features of this fluoride are further correlated to its spectroscopic properties obtained from IR and Raman studies completed with ${ }^{23} \mathrm{Na},{ }^{19} \mathrm{~F}$ and ${ }^{1} \mathrm{H}$ MAS-NMR spectroscopy. $\mathrm{NaNiF}_{3} \cdot 3 \mathrm{H}_{2} \mathrm{O}$ transforms into an orthorhombic sodium nickel fluoride with perovskite structure, similar to $\mathrm{NaNiF}_{3}{ }^{7}$, when heated to $200^{\circ} \mathrm{C}$.

\section{Experimental}

Synthesis of a Na-Ni-F compound with nominal composition " $\mathrm{NaNiF}_{3}$ " was attempted by precipitation from aqueous solution accordingly to the following chemical equation previously reported for the synthesis of $\mathrm{NaMF}_{3}$ perovskites ${ }^{2,13}$ :

$$
3 \mathrm{NaF}+\mathrm{NiCl}_{2} \cdot 6 \mathrm{H}_{2} \mathrm{O} \rightarrow " \mathrm{NaNiF}_{3} " \downarrow+2 \mathrm{NaCl}+6 \mathrm{H}_{2} \mathrm{O}
$$

$1.713 \mathrm{~g}\left(7.2 \cdot 10^{-3} \mathrm{~mol}\right)$ of $\mathrm{NiCl}_{2} \cdot 6 \mathrm{H}_{2} \mathrm{O}$ (Aldrich) were dissolved in $25 \mathrm{ml}$ distilled water. The stoichiometric amount of $\mathrm{NaF}\left(0.907 \mathrm{~g}, 21.6 \cdot 10^{-3} \mathrm{~mol}\right.$, Aldrich) was added to the green solution afterwards. The final solution was stirred for 6 hours and heated at $60^{\circ} \mathrm{C}$ to partially evaporate solvent until a light green powder precipitated. The precipitate was washed with small portions of distilled water and dried at $60^{\circ} \mathrm{C}$.

Chemical analysis was carried out to accurately determine the chemical composition of the compound and to confirm the structural model refined using X-ray and neutron diffraction data. $\mathrm{Na}$ and $\mathrm{Ni}$ contents were determined by means of ICP-OES (Perkin-Elmer). F/Na and $\mathrm{F} / \mathrm{Ni}$ atomic ratio and homogeneity of the sample was checked by electron probe microanalysis (EPMA) using a JEOL Superprobe JXA-8900 
M instrument equipped with wavelength dispersive spectrometry (WDS). Samples were pressed into pellets to get a planar surface. Quantitative determination was performed on the basis of $\mathrm{Na}, \mathrm{Ni}, \mathrm{O}$ and $\mathrm{F} \mathrm{X}$-ray emission lines using $\mathrm{NaF}, \mathrm{NiF}_{2}$ and $\mathrm{NiO}$ as reference compounds. The fluorine content was also quantified by $\mathrm{F}^{-}$titration with fluorine selective electrode measurements on samples that were previously digested with $\mathrm{HNO}_{3}$. Thermal analysis was carried out with a TGA/DTA Netzsch STA 409 apparatus. Samples were heated at $10 \mathrm{~K} \mathrm{~min}^{-1}$ up to $400^{\circ} \mathrm{C}$ under flowing nitrogen.

Powder X-ray diffraction patterns were recorded in the $10-100^{\circ} 2 \theta$ range on a Bruker D8 high resolution X-ray powder diffractometer, operated at $40 \mathrm{kV}$ and $40 \mathrm{mV}$ and equipped with a position sensitive detector (PSD) MBraun PSD50-M, using monochromatic $\mathrm{Cu}-\mathrm{K} \alpha$ radiation $(\lambda=1.54056 \AA)$ obtained with a Ge primary monochromator. The structure was deduced from powder X-ray diffraction (PXRD) data by using the $a b$ initio Expo2009 package. $^{14}$ For neutron powder diffraction (NPD) data were collected at the neutron source FRM II - MLZ (Garching, Germany) on the high resolution SPODI diffractometer. A Ge(551) monochromator was used to select a wavelength of $\lambda=1.5481 \AA$. Cylindrical vanadium cans of $8 \mathrm{~mm}$ diameter were filled with $3 g$ of powder sample. ND patterns were collected for 6 h over the $5-160^{\circ} 2 \theta$ range with a step size of $0.05^{\circ}$ at $300 \mathrm{~K}$.

The diffraction patterns were analyzed using the Rietveld technique as implemented in the Fullprof Suite Program. ${ }^{15,16}$ Peak shape was described by a pseudoVoigt function, and the background level was fitted with linear interpolation. The coherent neutron scattering lengths were: $\mathrm{H}:-3.74 \mathrm{fm}, \mathrm{O}:+5.803 \mathrm{fm}, \mathrm{F}:+5.654 \mathrm{fm}$, $\mathrm{Na}:+3.63 \mathrm{fm}, \mathrm{Ni}:+10.3 \mathrm{fm}^{17}$ The negative scattering length factor of hydrogen improves the contrast of light $\mathrm{O}$ and $\mathrm{F}$ elements, making possible Fourier map differences addressed to localize $\mathrm{H}$ atoms. 
Transmission electron microscopy (TEM) and electron diffraction (ED) experiments were performed with a JEOL 2000 FX microscope operating at $200 \mathrm{kV}$. Scanning electron microscopy (SEM) experiments were performed using a FEI XL30® apparatus equipped with an EDAX analyzer for energy dispersive spectroscopy (EDS).

IR spectroscopic data were collected on a FTIR Perkin Elmer 599 in the 4000$350 \mathrm{~cm}^{-1}$ range with a resolution of $4 \mathrm{~cm}^{-1} . \mathrm{KBr}$, previously dried, was used as reference. $150 \mathrm{mg}$ of a mixture of $\mathrm{KBr}$ and the as-synthesized material were pressed into $13 \mathrm{~mm}$ pellets inside an Ar-filled glove-box $\left(\mathrm{H}_{2} \mathrm{O}\right.$ content $\left.<1 \mathrm{ppm}\right)$. Raman spectra were taken in a DILOR XY spectrometer, with a CCD detector cooled with liquid nitrogen, using the $514.5 \mathrm{~nm}$ line of an $\mathrm{Ar}^{+}$laser as excitation source.

NMR experiments were carried out in an AVANCE 400 (Bruker) spectrometer. ${ }^{1} \mathrm{H}(\mathrm{I}=1 / 2),{ }^{23} \mathrm{Na}(\mathrm{I}=3 / 2)$ and ${ }^{19} \mathrm{~F}(\mathrm{I}=1 / 2)$ MAS-NMR spectra were recorded at 400.13, 105.84 and $376.50 \mathrm{MHz}$ respectively, in presence of the external magnetic field $\mathrm{B}_{0}$ $=9.4 \mathrm{~T}$. Samples were spun at $5 \mathrm{kHz}$ for ${ }^{1} \mathrm{H}, 10 \mathrm{kHz}$ for ${ }^{23} \mathrm{Na}$ and $20 \mathrm{kHz}$ for ${ }^{19} \mathrm{~F}$ around an axis inclined at $54^{\circ} 44^{\prime}$ with respect to the magnetic field (magic-angle spinning technique). ${ }^{1} \mathrm{H},{ }^{23} \mathrm{Na}$ and ${ }^{19} \mathrm{~F}$ chemical shift values of NMR components were referred to TMS, $\mathrm{NaCl}$ and $\mathrm{CFCl}_{3}$ standards.

Magnetic measurements were performed in a SQUID magnetometer (Quantum Design) MPMS-XL applying a field of 500 G. M/H measurements were performed using magnetic fields up to $5 \mathrm{~T}$ in the $2-400 \mathrm{~K}$ temperature range.

\section{Results}

Figure 1a shows the powder X-ray diffraction pattern of the green solid obtained after precipitation from aqueous solution following chemical equation (1). Its diffraction 
profile is quite different from that exhibited by $\mathrm{NaCoF}_{3}$ obtained by precipitation from solution (Figure 1b) and $\mathrm{NaNiF}_{3}$ samples obtained by the ceramic route (Figure 1c).

Both $\mathrm{NaCoF}_{3}$ and $\mathrm{NaNiF}_{3}$ are compatible with the perovskite structure and crystallize in the orthorhombic space group Pbnm. Refined lattice parameters were $a=$ 5.4244(5) $\AA, b=5.6066(6) \AA$ and $c=7.7925(8) \AA$ for $\mathrm{NaCoF}_{3}$, and $a=5.3690(4) \AA, b$ $=5.5290(2) \AA$ and $c=7.6950(3) \AA$ for $\mathrm{NaNiF}_{3}$. These values are in good agreement with those reported previously. ${ }^{8}$ Furthermore the X-ray diffraction pattern of $\mathrm{NaCoF}_{3}$ obtained by precipitation from solution completely agrees with that obtained by the high temperature ceramic route (not shown), yielding the same lattice parameters. In consideration of the above presented X-ray diffraction patterns, the crystalline precipitation product nominally formulated as " $\mathrm{NaNiF}_{3}$ " must then be structurally different from that of $\mathrm{NaMF}_{3}$ perovskites.

Chemical and thermal analyses

Wet chemical analysis of a sample showed the presence (in weight) of $12.9 \%$ sodium and $31.0 \%$ nickel, which correspond to an atomic Na:Ni ratio $=1.09: 1$. EDS spectra recorded in a transmission electron microscope showed signals corresponding to the elements $\mathrm{Na}, \mathrm{Ni}, \mathrm{F}$ and $\mathrm{O}$. The quantification of the metal atoms yielded a $\mathrm{Na} \mathrm{Ni}$ $=1: 1$ atomic ratio, in correspondence with results deduced by wet chemical analysis, although the actual $\mathrm{Na}$ content obtained from wet chemical analysis was slightly higher than that determined by EDS microanalysis performed on individual microcrystals. Results from X-ray diffraction revealed that the sample contains a small fraction of $\mathrm{NaF}$ as secondary phase (ca. 5\% as determined by Rietveld refinement). Based on this result the sodium weight $\%$ obtained from wet chemical analysis was recalculated to a $12.0 \%$ and an atomic Na:Ni ratio = 1:1. EPMA measurements showed the presence of a 1:1:3 
atomic ratio for the elements $\mathrm{Na}, \mathrm{Ni}$ and $\mathrm{F}$, in correspondence with the formula $\mathrm{NaNiF}_{3}$. However the compositional contributions of the three analyzed elements with their relative weight $\%$ ( $12.0 \%$ sodium, $31.0 \%$ nickel, $29.2 \%$ fluorine) amount to $72.2 \%$ of total mass), providing a conclusive proof that other components are contributing to the total mass. The hypothesis of assigning the remaining weight $\%$ to the presence of water molecules seemed reasonable from observations made during EDS measurements; prolonged exposure of a sample to the electron beam was accompanied by a continuous decrease of the oxygen signal, which may be related to evaporation of water from the sample during measurement. This behavior accounts for the general difficulties encountered during the study of this material by means of TEM and ED.

The presence of water has been investigated by thermal analysis. Figure 2 shows the variation of weight $\%$ with temperature up to $400{ }^{\circ} \mathrm{C}$ under flowing nitrogen. The important weight loss between 150 and $200^{\circ} \mathrm{C}(27.0 \%)$ can be related to the loss of three hydration water molecules. In consideration of a ca. $5 \% \mathrm{NaF}$ as secondary phase the recalculated weight loss was $28.2 \%$, which is in good agreement with the $28.0 \%$ calculated value for three water molecules. The formula $\mathrm{NaNiF}_{3} \cdot 3 \mathrm{H}_{2} \mathrm{O}$ is then confirmed by complementary analytical techniques. The effect of thermal dehydration on the structure has been studied by annealing $\mathrm{NaNiF}_{3} \cdot 3 \mathrm{H}_{2} \mathrm{O}$ to $250^{\circ} \mathrm{C}$ for $10 \mathrm{~h}$. The $\mathrm{X}$ ray pattern of the annealed sample was similar to that reported for orthorhombic $\mathrm{NaNiF}_{3}$, space group Pbnm, with the perovskite structure. A detailed study of the transformation of $\mathrm{NaNiF}_{3} \cdot 3 \mathrm{H}_{2} \mathrm{O}$ to orthorhombic perovskite will be reported elsewhere.

\section{Structural study}

The structure of the title compound was fully solved by combining different complementary techniques. Powder X-ray diffraction (PXRD) and neutron powder 
diffraction (NPD) data were treated using Expo2009 ${ }^{14}$ following the protocol implemented in this software. Electron diffraction was used to confirm the cell and symmetry determined by PXRD and NPD. Thus, first, the unit cell was determined from PXRD data using a new version of TREOR ${ }^{18}$ included in this package software. Two possible unit cells were obtained as solutions, a cubic one with $a \sim 7.90 \AA$ and a tetragonal one with $a \sim 5.60 \AA$ and $c \sim 7.90 \AA$. The dimensions of these two cells remind the double and diagonal $\mathrm{ReO}_{3}$-like cell, respectively. The double $\mathrm{ReO}_{3}$ supercell with cubic symmetry gave better figure of merit for indexing the PXRD pattern.

Electron diffraction patterns were collected to confirm the symmetry and space group of the supercell. A detailed observation of electron diffraction patterns assuming a basic $\mathrm{ReO}_{3}$-type structure revealed the presence of extra spots $(1 / 201 / 2)$ along the [010] zone axis and [-111] zone axes (which are 4- and 3-fold axes characteristic of cubic symmetry), suggesting a cubic superstructure with doubled $a$ parameter (a $8 \AA$ ). Figure 3 shows selected area electron diffraction (SAED) images obtained for $\mathrm{NaNiF}_{3} \cdot 3 \mathrm{H}_{2} \mathrm{O}$, which were indexed on the basis of this cubic supercell along the [010] zone axis (Fig. 3a). The lack of integral extinction conditions indicates that it has a primitive cubic space group. Using the aforementioned cell, the extinction symbol resulted to be $P n$. Further patterns were collected along the [-110], [-120], [-111] zone axes (Figure 3b-d), which identified the remaining symmetry elements. The presence of extinction conditions for $(0 k l) k+l=2 \mathrm{n} ;(00 l) l=2 \mathrm{n}$ lead to two possible space groups, $P n-3\left(\mathrm{n}^{\mathrm{o}} 201\right)$ and $P n-3 m\left(n^{\circ} 224\right)$. Forbidden odd $h$ reflections for $h 00$ on [-110] and for $00 l$ on [-111] patterns are caused by double diffraction. This was confirmed by tilting the crystal along the row containing the forbidden reflections, whose intensities varied significantly. 
At this point we assessed that the $2 a \times 2 a \times 2 a$ supercell ( $a$ being the simple $\mathrm{ReO}_{3}$ axis) is only compatible with $P n-3$ symmetry, involving the $a^{+} a^{+} a^{+}$octahedra tilting scheme and 1:1 cation ordering on the octahedral sites. ${ }^{19,20}$ This symmetry was then used for intensity extraction and structure solution by direct methods. EXPO2009 yielded the following three atoms: $\mathrm{Ni}, \mathrm{Na}$ and $\mathrm{F}$ in Wyckoff positions $4 \mathrm{~b}, 4 \mathrm{c}$ and $24 \mathrm{~h}$, respectively. At this stage all anions were supposed to be fluorine atoms, but from chemical and TG analyses the composition of the parent compound was known to contain an equiatomic amount of oxygen atoms, at least nominally as water molecules, according to the formula $\mathrm{NaNiF}_{3} \cdot 3 \mathrm{H}_{2} \mathrm{O}$. As oxygen and fluorine atoms cannot be distinguished by powder X-ray diffraction, we assumed a random distribution of both atom types on the same crystallographic $24 \mathrm{~h}$ site. Using this model as starting point, the PXRD and NPD patterns were simultaneously fitted with the same weight. Neutron diffraction cannot either provide extra information about possible $\mathrm{O} / \mathrm{F}$ ordering, owing to their very similar neutron scattering lengths $(\mathrm{O}:+5.803 \mathrm{fm}, \mathrm{F}:+5.654 \mathrm{fm})$. On the other hand, neutron powder diffraction is a useful technique to obtain accurate and precise information about weak X-ray scatterers, especially hydrogen. The negative scattering length factor of hydrogen $(\mathrm{H}:-3.74 \mathrm{fm})$ improves even the contrast of light $\mathrm{O}$ and $\mathrm{F}$ elements, making possible Fourier map differences addressed to localize $\mathrm{H}$ atoms. Details about experimental conditions and refined parameters are given in Table 1, whereas the main structural parameters of the refined model are summarized in Table 2 together with bond distances and angles in Table 3 . The graphic result of the fitting of NPD data is depicted in Figure 4. The corresponding graphic result of the fitting of PXRD data is given as Supplementary Information Figure SI 1. The second phase included in the refinement corresponds to $\mathrm{NaF}$, which is formed to a small extent (ca. $5 \%$ ) during the precipitation reaction from aqueous solution. 
The structure of $\mathrm{NaNiF}_{3} \cdot 3 \mathrm{H}_{2} \mathrm{O}$ is built from corner-sharing $\mathrm{Ni}(\mathrm{O} / \mathrm{F})_{6}$ and $\mathrm{Na}(\mathrm{O} / \mathrm{F})_{6}$ octahedra that alternate along the three main directions (Figure 5). Oxygen and fluorine atoms are randomly distributed in the nonmetal $24 \mathrm{~h}$ position. $\mathrm{NaNiF}_{3} \cdot 3 \mathrm{H}_{2} \mathrm{O}$ corresponds to a fully cation ordered variant of the $\mathrm{Sc}(\mathrm{OH})_{3}{ }^{21}$ or $\operatorname{In}(\mathrm{OH})_{3}{ }^{22,23}$ structure, what is better formulated as $\mathrm{NaNi}(\mathrm{XH})_{6}(\mathrm{X}=\mathrm{O}, \mathrm{F})$. In comparison to $\operatorname{In}(\mathrm{OH})_{3}$ the decrement of three positive charges produced by substituting two $\mathrm{In}^{3+}$ ions by one $\mathrm{Na}^{+}$ and one $\mathrm{Ni}^{2+}$, is compensated by the substitution of $3 \mathrm{O}^{2-}$ by $3 \mathrm{~F}^{-}$. Each $(\mathrm{O} / \mathrm{F}) \mathrm{H}$ is coordinated with one $\mathrm{Na}^{+}$and one $\mathrm{Ni}^{2+}$ to form zigzag-like infinite $\mathrm{Na}-(\mathrm{O} / \mathrm{F})-\mathrm{Ni}$ chains, with a Na-O/F-Ni angle of $129.4(1)^{\circ}$. This angle is similar to that detected in $\operatorname{In}(\mathrm{OH})_{3}$, 134.6(1) ${ }^{\mathrm{o}}$, where hydrogen bonding is determinant to produce the bending of M-X-M chains ${ }^{22,23}$.

The Ni-O/F bond distance of $2.029(2) \AA$ is clearly shorter than the Na-O/F distance of 2.348(2) $\AA$, in agreement with ionic sizes of hexacoordinated $\mathrm{Ni}^{2+}$ and $\mathrm{Na}^{+}$ (0.69 $\AA$ and $1.02 \AA$, respectively). ${ }^{24}$ The nickel to anion and sodium to anion bond distances are intermediate between the corresponding metal-oxygen and metal-fluorine distances, owing to the $(\mathrm{O} / \mathrm{F})$ mixed anion substructure. In $\mathrm{NaNi}(\mathrm{XH})_{6}(\mathrm{X}=\mathrm{O}, \mathrm{F})$ the $\mathrm{Ni}$ $\mathrm{O} / \mathrm{F}$ bond distance of 2.029(2) $\AA$ is slightly shorter than the Ni-O bond distance found in $\mathrm{NiO}(2.089 \AA)$ or $\beta-\mathrm{Ni}(\mathrm{OH})_{2}(2.093-2.136 \AA)^{25}$, whereas this value is slightly larger than the Ni-F bond distances determined in $\mathrm{KNiF}_{3}(2.006 \AA)^{2}$ or $\mathrm{K}_{2} \mathrm{NiF}_{4}(1.974-2.004$ $\AA)^{26}$. Likewise the Na-O/F bond distance of 2.348(2) $\AA$ is shorter than the Na-O bond distance observed in $\alpha-\mathrm{NaOH}(2.350-2.426 \AA)^{27}$ or $\mathrm{NaCoO}_{2}(2.375 \AA)^{28}$, while the Na$\mathrm{O} / \mathrm{F}$ distance is systematically longer than the Na-F distance determined in $\mathrm{NaF}(2.316$ $\AA)^{29}$ or in the high temperature form of $\mathrm{Na}_{3} \mathrm{AlF}_{6}(2.305 \AA)^{30}$. 
Magnetic characterization

The variation of the magnetic susceptibility of $\mathrm{NaNi}(\mathrm{XH})_{6}(\mathrm{X}=\mathrm{O}, \mathrm{F})$ versus temperature is shown in Figure 6. Fit of experimental data to

$$
\chi_{m}=\frac{C}{T-\theta}
$$

yielded a Curie constant $\mathrm{C}=1.20$ and a Weiss constant $\theta=0.10 \mathrm{~K}$. The compound $\mathrm{NaNiF}_{3} \cdot 3 \mathrm{H}_{2} \mathrm{O}$ shows then a Curie-like behaviour. No deviation of $1 / \chi_{\mathrm{m}}$ vs. T (inset to Fig. 6) from linearity is observed in the whole temperature range. The experimental magnetic moment $\mu_{\exp }=3.0 \mu_{\mathrm{B}}$ corresponds to two unpaired electrons for an octahedrally co-ordinated $d^{8} \mathrm{Ni}^{2+}$ cation, in good agreement with the expected magnetic moment $\left(\mu_{\mathrm{s} . \mathrm{o}}=2.82 \mu_{\mathrm{B}}\right)$.

The negligible $\theta$ value confirms the lack of any significant interaction between paramagnetic centres. This is easily understood when recalling that the $\mathrm{Ni}(\mathrm{O} / \mathrm{F})_{6}$ octahedra are isolated from each other by $\mathrm{Na}(\mathrm{O} / \mathrm{F})_{6}$ octahedra due to the particular alternating ... $\mathrm{Na}-\mathrm{Ni}-\mathrm{Na}$...cation ordering along the three directions of this $\mathrm{ReO}_{3}$-type structure. The observed magnetic behaviour then supports the presence of isolated paramagnetic $\mathrm{Ni}(\mathrm{O} / \mathrm{F})_{6}$ units. This behaviour is quite opposite to the antiferromagnetic ordering displayed by $\mathrm{NaNiF}_{3}$ perovskite ${ }^{7}$, where exchange interaction of $\mathrm{Ni}$ through $p$ orbitals of fluorine through corner-shared $\mathrm{NiF}_{6}$ octahedra does occur.

\section{Discussion}

The $\mathrm{ReO}_{3}$-type supercell in $\mathrm{NaNi}(\mathrm{XH})_{6}(\mathrm{X}=\mathrm{O}, \mathrm{F})$ with doubling of the cubic $a$ parameter arises from a combined effect of 1:1 cation ordering on the Re site and octahedral tilting. Ordering in the B-site of the perovskite structure is very well known for cations differing in charge (by at least two units) or having very different size. In the present case, the driving force for ordering seems to be more likely different size effect 
than charge, taking into consideration that $\mathrm{Na}^{+}(102 \mathrm{pm})$ is $48 \%$ bigger than $\mathrm{Ni}^{2+}(69$ pm) (both in 6-fold coordination) ${ }^{24}$. A complete symmetry relationship among $\mathrm{ReO}_{3}$ derivatives based on group-subgroup relations was reported by Bock ${ }^{31}$. For clarity the relationship between the $\mathrm{ReO}_{3}$ structure type and the corresponding derived supercells owing to the present case of $a^{+} a^{+} a^{+}$octahedral tilting without and with 1:1 cation ordering is portrayed in Figure 7. According to the works of Glazer ${ }^{9}$ and Woodward ${ }^{19}$ $a^{+} a^{+} a^{+}$in-phase octahedral tilting of the basic primitive $\operatorname{ReO}_{3}$ structure $\left(a^{0} a^{0} a^{0}, P m-3 m\right)$ leads to a $2 a \times 2 a \times 2 a$ supercell, space group $I m-3$, realized in $\mathrm{HNbO}_{3}{ }^{32}$, the high pressure form of $\mathrm{ReO}_{3}{ }^{33}, \mathrm{Sc}(\mathrm{OH})_{3}{ }^{21}$ and $\mathrm{In}(\mathrm{OH})_{3}{ }^{22,23}$. $\mathrm{NaNiF}_{3} \cdot 3 \mathrm{H}_{2} \mathrm{O}$ is one of the rare examples for $a^{+} a^{+} a^{+}$octahedral tilting combined with $1: 1$ cation ordering in the $\mathrm{ReO}_{3}$ structure, resulting in a $2 a \times 2 a \times 2 a$ cell with space group $P n-3$. Only $\mathrm{CaSn}(\mathrm{OH})_{6}$ (burtite) and six other isotypic hydroxides have been reported so far to crystallize with the same structure ${ }^{34-36}$. However, $\mathrm{NaNiF}_{3} \cdot 3 \mathrm{H}_{2} \mathrm{O}$ compound is the first example for this cation ordered structure type with concurrent anion disorder.

The tight $\mathrm{Na}-\mathrm{X}-\mathrm{Ni}$ bond angle detected in $\mathrm{NaNi}(\mathrm{XH})_{6}, 129.4^{\circ}$, is related with a considerable tilting angle of $31^{\circ}$. In the notation of Glazer small rotations of regular octahedra with uniform $\mathrm{M}-\mathrm{X}-\mathrm{M}(\mathrm{M}=$ metal, $\mathrm{X}=$ non-metal) angles, $\theta$, correspond to rotations about $\langle 111\rangle$. In order to address the question whether the observed tilting distortion is related to the geometry (different cation size) or further enhanced by hydrogen bonding, we have collected $\mathrm{M}-\mathrm{X}-\mathrm{M}$ bond angles $\theta$ and deduced the rotation angle $\varphi$ about $<111>$ for a series of $\mathrm{ReO}_{3}$ related compounds. Tilting angles $\varphi$ have been calculated using the formula given by Keeffe and Hyde ${ }^{37}$ :

$$
\theta=\cos ^{-1}\left|\frac{1-2 \cdot(2 \cdot \cos \varphi+1)^{2}}{9}\right|
$$


In our analysis we have only considered $a^{+} a^{+} a^{+}$tiltings for regular octahedra with a uniform bond angle, which correspond strictly to rotations about $<111\rangle$ (besides the $a^{-} a^{-} a^{-}$tilting). Results are given in Table $4 . \mathrm{ReO}_{3}{ }^{38}$ itself undergoes $a^{+} a^{+} a^{+}$tilting of octahedra under pressure. ${ }^{33}$ For $a^{+} a^{+} a^{+}$tilting the octahedra rotation is such that four octahedron corners close up, resulting in nearly square $\mathrm{X}_{4}$ units $(\mathrm{X}=$ =anion). Larger rotation angles have been reported to arise from additional $\mathrm{X}-\mathrm{X}$ bonding. The quite considerable octahedra rotation in skutterudite $\operatorname{CoAs}_{3}\left(\varphi=33^{\circ}\right)$ has been connected with the formation of square $\mathrm{As}_{4}{ }^{4-}$ units. ${ }^{39}$ Analogous square $(\mathrm{OH})_{4}{ }^{4-}$ units, with hydrogen bonding along the square edges, are obtained in oxy-hydroxide $\mathrm{NbO}_{2}(\mathrm{OH})^{32}$ and hydroxides $\mathrm{Sc}(\mathrm{OH})_{3}{ }^{21}$ and $\operatorname{In}(\mathrm{OH})_{3}{ }^{23}$. Not surprisingly, the stronger hydrogen bonding in $\mathrm{Sc}(\mathrm{OH})_{3}$ and $\mathrm{In}(\mathrm{OH})_{3}$ produces bigger tilting angles $\left(\varphi=24.0\right.$ and $27.9^{\circ}$, respectively). The 1:1 cation substitution in $\operatorname{ReO}_{3}$ leads to $\mathrm{NaSbF}_{6}\left(a^{0} a^{0} a^{0}\right) .^{40}$ The $a^{+} a^{+} a^{+}$tilting of the $\mathrm{NaSbF}_{6}$ structure is realized in burtite $\mathrm{CaSn}(\mathrm{OH})_{6}{ }^{34,35}$ and the isostructural hydroxides $\mathrm{MSn}(\mathrm{OH})_{6}(\mathrm{M}=\mathrm{Mn}, \mathrm{Zn}){ }^{34-36}$ with $\varphi \sim 27^{\circ}$, similar to $\mathrm{M}(\mathrm{OH})_{3}$. We can preclude different cation size as origin for the observed octahedra titlting; $\mathrm{NaSbF}_{6}$ is not tilted, however the hydroxides with comparable cation radii ${ }^{24}\left(\mathrm{Na}^{+}: 1.02 \AA ; \mathrm{Ca}^{2+} 1.00 \AA\right.$; $\mathrm{Sb}^{5+}: 0.60 \AA$; $\mathrm{Sn} 4+: 0.69 \AA$ ) are tilted, as consequence of hydrogen bonding in the hydroxides. Based on the ionic radii ${ }^{24}$ for $\mathrm{Na}^{+}: 1.02 \AA$ and $\mathrm{Ni}^{2+}: 0.69 \AA$, the larger rotation angle $\varphi=31^{\circ}$ leads us to assume stronger hydrogen bonding in $\mathrm{NaNi}(\mathrm{XH})_{6}$. On the other hand, the high-pressure form of $\mathrm{NbO}_{2} \mathrm{~F} \quad\left(\varphi=18-22^{\circ}\right)^{41,42}$ and several trifluorides such as $\mathrm{FeF}_{3}{ }^{43}$ at normal pressure are examples for the $a^{-} a^{-} a^{-}$tilted hettotype. Interestingly, though considerable octahedra titlting is well known for trifluorides such as $\mathrm{PdF}_{3}{ }^{44}\left(\varphi=30^{\circ}\right)$, enhanced octahedral rotation due to hydrogen bonding has not been observed for the $a^{-} a^{-} a^{-}$hettotype. This may be related to the 
corrugated rhombus-like arrangement of anion corners resulting from this type of rotation that likely hinders formation of hydrogen bonds.

The octahedral tilts in $\mathrm{NaNi}(\mathrm{XH})_{6}$ produce two short interanionic distances (2.559 and 2.789 A, see Figure 5) between adjacent O/F atoms belonging to two linked $\mathrm{Ni}(\mathrm{O} / \mathrm{F})_{6}-\mathrm{Na}(\mathrm{O} / \mathrm{F})_{6}$ octahedra. A similar situation has been reported in $\mathrm{Sc}(\mathrm{OH})_{3}{ }^{21}$ and $\mathrm{In}(\mathrm{OH})_{3}{ }^{22}$ which may be considered isotypic when disregarding the additional cation ordering in $\mathrm{NaNi}(\mathrm{XH})_{6}(\mathrm{X}=\mathrm{O}, \mathrm{F})$. In the $\mathrm{NaNiF}_{3} \cdot 3 \mathrm{H}_{2} \mathrm{O}$ structure the difference on the $\mathrm{Na}$ and $\mathrm{Ni}$ charge could justify the location of $\mathrm{Na}$ in F-rich environments and $\mathrm{Ni}$ cations in O-rich environments. However, all anions are bonded to $1 \mathrm{Na}^{+}$and $1 \mathrm{Ni}^{2+}$ cations, making that this asymmetric arrangement cannot be adopted.

Two hydrogen positions have been located during the refinement of neutron data by Fourier difference maps. The hydrogen sites are disordered and found close to the mixed $(\mathrm{O} / \mathrm{F})$ anion site to give sets of short (1.05 $\AA$; covalent bonding) and large (1.50 and $1.75 \AA$; $\mathrm{H}$ bonding) distances. Figure $8 \mathrm{~b}$ shows the hydrogen atom distribution in the $\mathrm{NaNi}(\mathrm{XH})_{6}(\mathrm{X}=\mathrm{O}, \mathrm{F})$ structure. For comparison the analogous distribution observed in $\mathrm{In}(\mathrm{OH})_{3}$ is displayed (Fig. 8a). However these disordered $\mathrm{H}$ positions are too close to each other to be simultaneously occupied (that would produce impossible short distances from 0.50 to $0.70 \AA$ ). Half occupancy for both $\mathrm{H}$ sites has been adopted in structural refinements. The only atomic arrangement consistent with the composition is that each pair of neighboring anions is bridged by a proton, making a short bond to one and a long bond to the other. This arrangement would be only consistent with the formulation $\mathrm{NaNiF}_{3}\left(\mathrm{H}_{2} \mathrm{O}\right)_{3}$, if the $\mathrm{O}$ and $\mathrm{F}$ anions are ordered, producing always short $\mathrm{OH}$ and long $\mathrm{FH}$ bonds. However, assuming that the anion lattice is disordered, the compound has to be formulated as $\mathrm{NaNi}(\mathrm{XH})_{6}(\mathrm{X}=\mathrm{O}, \mathrm{F})$. 
As result from considerable octahedra tilting in $\mathrm{NaNi}(\mathrm{XH})_{6}$, isolated square $(\mathrm{XH})_{4}{ }^{4-}$ units of disordered $\mathrm{O} / \mathrm{F}$ anions $\mathrm{X}$ are formed, with hydrogen bonding along the square edges. These extend perpendicular to each other along the three main directions (Fig. 8c). The average anion distances in the square motifs, 2.559(3) and 2.789(3) $\AA$, are significantly different and can be interpreted as being related to the strength of hydrogen bonds. The strength of hydrogen bonding has been related to the $\mathrm{O}-\mathrm{H} \cdots \mathrm{O}$ angle and the corresponding intermolecular $\mathrm{O} \cdots \mathrm{O}$ distance ${ }^{45,46}$. In the present case, both hydrogen bonds seem to be fairly strong, although stronger hydrogen bonding related to $\mathrm{H} 1$ is deduced. The $\mathrm{O} / \mathrm{F}-\mathrm{H} 1 \cdots \mathrm{O} / \mathrm{F}$ angle is closer to $180^{\circ}\left(173.7^{\circ}\right)$ and the corresponding $\mathrm{O} / \mathrm{F} \cdots \mathrm{O} / \mathrm{F}$ bond distance shorter $(2.559 \AA$ ). Being both $\mathrm{O} / \mathrm{F}-\mathrm{H}$ covalent bond distances nearly the same $(\sim 1.05 \AA)$, the $\mathrm{O} / \mathrm{F} \cdots \mathrm{H} 2$ acceptor bond length increases $(\sim 1.75 \AA)$ and is then weaker with respect to $\mathrm{O} / \mathrm{F} \cdots \mathrm{H} 1(\sim 1.50 \AA)$.

\section{NMR Spectroscopy}

Spectroscopic measurements have been undertaken with the purpose of validating the conclusions derived from ND, namely the random occupancy of $\mathrm{F}$ and $\mathrm{O}$ anions in a single site and proton distribution in different anion environments. For that, the NMR study of the ${ }^{19} \mathrm{~F},{ }^{23} \mathrm{Na}$ and ${ }^{1} \mathrm{H}$ signals corresponding to $\mathrm{NaNi}(\mathrm{XH})_{6}(\mathrm{X}=\mathrm{O}, \mathrm{F})$ has been performed with the high resolution Magic Angle Spinning (MAS-NMR) technique. The MAS technique is particularly adapted to improve the spectral resolution, due to the partial cancelation of diamagnetic F-Na, F-F and F-H and paramagnetic F-Ni and $\mathrm{H}-\mathrm{Ni}$ dipolar interactions with $3.0 \mu_{\mathrm{B}}$ of $\mathrm{Ni}^{2+}\left(d^{8}\right)$ cations, which broaden NMR signals.

The ${ }^{23} \mathrm{Na}$ MAS-NMR spectrum of $\mathrm{NaNiF}_{3} \cdot 3 \mathrm{H}_{2} \mathrm{O}$ compound depicted in Figure 9 shows the presence of two different signals at 8 and $308 \mathrm{ppm}$. The narrow signal at 8 
ppm can be ascribed to the presence of a small amount of $\mathrm{NaF}^{47}$, which was formed during the sample preparation, already detected by XRD technique. In this case, Na environment is symmetric and no quadrupolar patterns were detected.

The broad signal at $308 \mathrm{ppm}$ contains the central $(1 / 2,-1 / 2)$ and satellite $(3 / 2$, 1/2) transitions, modulated by the spinning sidebands produced by the sample rotation $(20 \mathrm{kHz})$. This band has been ascribed to the octahedral coordination of sodium. ${ }^{48}$ The analysis of the spinning sideband pattern using first order quadrupolar interactions shows that the recorded spectrum is reproduced by assuming a quadrupolar $\mathrm{C}_{\mathrm{Q}}$ constant of $0.47 \mathrm{MHz}$ and an asymmetric $\eta$ parameter of 0.6 . The detection of satellite quadrupolar transitions suggests the existence of an asymmetric distribution of $\mathrm{F}$ and $\mathrm{O}$ ions around $\mathrm{Na}$ cations. A disordered distribution of anions could explain local asymmetries detected in the Na signal.

The ${ }^{19} \mathrm{~F}$ MAS-NMR spectrum of $\mathrm{NaNi}(\mathrm{XH})_{6}(\mathrm{X}=\mathrm{O}, \mathrm{F})$ depicted in Figure 10 shows the presence of three different signals at $-123,-151$ and $-221 \mathrm{ppm}$ (denoted by horizontal arrows), that are accompanied by their corresponding rotational bands (stars, circles and diamonds, respectively). The analysis of the complex $-221 \mathrm{ppm}$ signal suggests the presence of two components that we attribute to F-rich environments in $\mathrm{NaF}$ and $\mathrm{NaNi}(\mathrm{XH})_{6}$ compounds. $^{47}$

Taking into account that all anions are surrounded by one sodium and one nickel atom in $\mathrm{NaNi}(\mathrm{XH})_{6}$, chemical shifts of signals should be ascribed to differences on anion environment. Based on the structural arrangement of octahedra - each F should have ten next nearer $\mathrm{F} / \mathrm{OH}$ anions as neighbors -, the number of detected environments should be very high. However, the number of detected bands is considerably lower than expected, indicating that octahedral distortions and tiltings detected in structural refinements reduce the number of anion environments. 
If we analyze the structure of $\mathrm{NaNi}(\mathrm{XH})_{6}(\mathrm{X}=\mathrm{O}, \mathrm{F})$, we observe the presence of separated anion square associations (Figure 8) where each corner may be occupied by F or $\mathrm{O}$ with equal probability. The probability of occurrence of squares with a given number of $\mathrm{F}$ and $\mathrm{O}$ anions can be worked out by means of the binomial formula, according to which the multiplicity of $4 \mathrm{~F}$ and $4 \mathrm{O}$ squares should be $6.25 \%$, that of $2 \mathrm{~F}+2 \mathrm{O}$ squares is $37.5 \%$ and that of $3 \mathrm{~F}+1 \mathrm{O}$ and $1 \mathrm{~F}+3 \mathrm{O}$ is of $25 \%$. Based on these multiplicities and the possible arrangements of $\mathrm{F}$ and $\mathrm{O}$ within them, we have ascribed the three signals at $-123,-151$ and -221 ppm to O-F-O, O-F-F and F-F-F environments in square associations. Taking into account probabilities deduced for these different environments, the presence of O-O-O and F-F-F environments results improbable. The quantitative analysis of the three detected signals, 20, 70 and 10\%, suggests the presence of a disordered distribution of anions in square associations. An alternating $\mathrm{O}^{2-}$ and $\mathrm{F}^{-}$ordered distribution should produce a single component in the $\mathrm{F}$ signal that was not observed.

The presence of diamagnetic $\mathrm{H}-\mathrm{H}, \mathrm{H}-\mathrm{F}$ and paramagnetic $\mathrm{H}-\mathrm{Ni}$ interactions enlarge considerably ${ }^{1} \mathrm{H}$ MAS-NMR spectra of $\mathrm{NaNi}(\mathrm{XH})_{6}$. In order to improve spectral resolution, experiments were conducted at two spinning rates in two different probes. Best results were obtained in a $7 \mathrm{~mm}$ diameter probe, where a higher amount of sample was used. In this case, the smaller electrical probe background favors the detection of three components at 2, 5 and $7 \mathrm{ppm}$ (Figure 11). In this spectrum, dipolar interactions produce an important amount of spinning side bands separated by the spinning rate, $5000 \mathrm{c} / \mathrm{s}$. The ${ }^{1} \mathrm{H}$ MAS-NMR signal recorded in the $4 \mathrm{~mm}$ probe at $14000 \mathrm{c} / \mathrm{s}$ rotor speed displays again 2, 5 and 7 ppm components, but with a lower amount of spinning sidebands. 
Taking into account the location of protons between two nearest $\mathrm{O} / \mathrm{F}$ anions of contiguous octahedra, the three detected bands can be tentatively ascribed to protons within $\mathrm{O} \ldots \mathrm{O}, \mathrm{O} \ldots \mathrm{F}$ and $\mathrm{F} \ldots \mathrm{F}$ associations. In general, $\mathrm{OH}$ bonds are stronger than $\mathrm{FH}$ bonds, so that if a proton is covalently bonded to oxygen the hydrogen bond with the acceptor atom will be weaker compared with the case in which the covalent bond is with a fluorine anion. Based on this fact, the most intense $2 \mathrm{ppm}$ band has been ascribed to protons in $\mathrm{O} \ldots \mathrm{O}$ and those at 5 and $7 \mathrm{ppm}$ to $\mathrm{O} \ldots \mathrm{F}$ and $\mathrm{F} \ldots \mathrm{F}$ environments (Figure 11). The relative intensities of the three bands indicate that the probability of the three environments differs considerably from calculations based on the random proton distribution in the three considered associations. This suggests that other aspects such as the asymmetric distribution of protons with respect to $\mathrm{O}^{2-}$ and $\mathrm{F}^{-}$anions or local motions could affect the analysis of intensities. In particular, the preferential association of protons with oxygen could favor the formation of $\mathrm{H}_{2} \mathrm{O}$ molecules (band at $5 \mathrm{ppm}$ ) in contiguous $\mathrm{O}^{2-}-\mathrm{F}^{-}$pairs. However, the intensity of this band is small.

IR and Raman spectroscopy

Raman spectra recorded in a $\mathrm{NaNiF}_{3} \cdot 3 \mathrm{H}_{2} \mathrm{O}$ single crystal are depicted in Figure 12. Taking into account the atomic occupancies in the $P n-3$ unit cell and assuming a random distribution of $\mathrm{F}$ and $\mathrm{O}$ in the anion sites, 15 Raman active modes $\left(3 \mathrm{~A}_{\mathrm{g}}+3 \mathrm{E}_{\mathrm{g}}+\right.$ $9 \mathrm{~F}_{\mathrm{g}}$ ) are expected, which arise exclusively from $\mathrm{O} / \mathrm{F}$ anions. $\mathrm{Na}$ and $\mathrm{Ni}$ do not participate in Raman active modes because they are located at sites with inversion symmetry. Protons are not considered in this calculation.

Though apparently the number of observed modes agrees with the expectations, this coincidence is misleading. The prediction of 15 Raman active modes is based on the assumption of a single (or average) type of anion. However, because of the charge 
difference, the vibrations arising from $\mathrm{F}^{-}$and $\mathrm{O}^{2-}$ are not expected to mix as in a onemode behaviour. A multiplication of the number of modes is rather expected. The number of modes observed is incompatible with a well-ordered, periodic structure, but it can neither be explained by a completely disordered one, which would yield much broader and ill-defined bands. We therefore propose that the ordered aspect of Raman spectra arises from local configurations with short-range F/O ordering, similar to reports on other systems ${ }^{49,50}$.

Figure 13a shows the IR spectrum of $\mathrm{NaNi}(\mathrm{XH})_{6}(\mathrm{X}=\mathrm{O}, \mathrm{F})$ in the $350-4000 \mathrm{~cm}^{-1}$ range. We divide the spectrum into two regions, above and below $2000 \mathrm{~cm}^{-1}$, pertaining to stretching and bending-like vibrations of systems involving protons. The stretching region shows two intense though structured bands, peaked at about 3300 and $3000 \mathrm{~cm}^{-1}$, and a doublet centred at $2300 \mathrm{~cm}^{-1}$. The weak band at $3630 \mathrm{~cm}^{-1}$ is assigned to a "free" hydroxyl group from a residual $\mathrm{Ni}(\mathrm{OH})_{2}$ phase $\left(\mathrm{v}_{\mathrm{OH}^{-}}=3637 \mathrm{~cm}^{-1}\right){ }^{51}$

The broad aspect and the intensity of the bands in the stretching region suggest the occurrence of significant hydrogen bonds. This is not surprising in view of the short intermolecular distances $\mathrm{d}_{1} \approx 2.56$ and $\mathrm{d}_{2} \approx 2.79 \AA$ between anions of adjacent octahedra, where protons are located (see Figure 8). To make the discussion clearer, we use the notation D-H...A for each configuration of hydrogen-bonded D and A anions, where D and A stand for proton donor or acceptor. $\mathrm{In} \mathrm{NaNi}(\mathrm{XH})_{6} \mathrm{H}$ stands for either $\mathrm{H}_{1}$ or $\mathrm{H}_{2}$ depending on whether the D-A distance is $\mathrm{d}_{1}$ or $\mathrm{d}_{2}$, respectively.

Oxide ions act either as donors or as acceptors in a great variety of $\mathrm{H}$ bonds; however the behaviour of fluoride ions depends on which is the other element involved in the bond. To our knowledge, fluorine never acts as donor in hydrogen bonds involving $\mathrm{O}$. With these ideas in mind, we start the analysis with protons covalently bonded to oxygen atoms in $\mathrm{O}-\mathrm{H} . . \mathrm{O}$ configurations. ${ }^{52,53}$ Using the expression $v_{\mathrm{O}-\mathrm{H}}=$ 
$3592-304 \times 10^{9} \exp (-\mathrm{d} / 0.1321)$ given in ${ }^{52}$ we obtain $v_{\mathrm{O}-\mathrm{H}, 1}=2426 \mathrm{~cm}^{-1}$ and $v_{\mathrm{O}-\mathrm{H}, 2}=3388$ $\mathrm{cm}^{-1}$ for $\mathrm{d}_{1}=2.56 \AA\left(\mathrm{O}-\mathrm{H}_{1} \ldots \mathrm{O}\right)$ and $\mathrm{d}_{2}=2.9 \AA\left(\mathrm{O}-\mathrm{H}_{2} \ldots \mathrm{O}\right)$, respectively, in good agreement with experimental results, specifically with bands centred at 3300 and 2300 $\mathrm{cm}^{-1}$.

In $\mathrm{O}-\mathrm{H} . . . \mathrm{F}$ configurations an increase of $\mathrm{v}_{\mathrm{O}-\mathrm{H}}$ is expected, since the $\mathrm{OH}$-bond becomes stronger than in $\mathrm{O}-\mathrm{H} . . . \mathrm{O}$ associations. A difference of about $100 \mathrm{~cm}^{-1}$ is found between the O-D stretching frequencies in O-D...F and O-D...O bonds. ${ }^{54}$ Assuming that the frequencies will increase proportionally for proton vibration, a hardening of about $140 \mathrm{~cm}^{-1}$ can be expected for O-H...F with respect to O-H...O. These differences fit reasonably well within the multiple component aspect of the band at $3300 \mathrm{~cm}^{-1}$, now assigned to both $\mathrm{O}-\mathrm{H}_{2} \ldots \mathrm{F}$ and $\mathrm{O}-\mathrm{H}_{2} \ldots \mathrm{O}$, and nicely explain the splitting of the 22302390 bands, which are then assigned to both $\mathrm{O}-\mathrm{H}_{1} \ldots \mathrm{F}$ and $\mathrm{O}-\mathrm{H}_{1} \ldots \mathrm{O}$ bonds.

Finally we consider the cases with fluorine as a donor, F-H...A. As explained above, a proton located between $\mathrm{F}$ and $\mathrm{O}$ is expected to shift toward the oxygen, thus contributing to the band above $3200 \mathrm{~cm}^{-1}$. If both anions are $\mathrm{F}$, the strength of the $\mathrm{H}$ bonds depends critically on the F...F distance. ${ }^{55}$ In our case, both $\mathrm{d}_{1}$ and $\mathrm{d}_{2}$ are much higher than the short distances involved in symmetric F-H-F bonds ${ }^{56,57}$, so that protons will probably remain close to one of the fluorine ions, resulting in a relatively high stretching frequency that we identify with the band appearing at about $3000 \mathrm{~cm}^{-1}$. We then attribute this band to $\mathrm{F}-\mathrm{H}_{1} \ldots \mathrm{F}$ and $\mathrm{F}-\mathrm{H}_{2} \ldots \mathrm{F}$ configurations.

In the bond-bending region we find a strong band at $1578 \mathrm{~cm}^{-1}$ and other bands at lower frequencies. The region around $1600 \mathrm{~cm}^{-1}$ readily suggests the presence of water-like entities. As we have said, in asymmetric F...O configurations the proton will shift toward the oxygen, but this oxygen may be already bonded to another proton at 
approximate right angles from the first bond. Thus, the presence of fluoride ions near oxygen atoms favours water-like configurations of $\mathrm{H}_{1}-\mathrm{O}-\mathrm{H}_{2}$ type.

Nevertheless, the frequency of $1578 \mathrm{~cm}^{-1}$ is lower than typical values observed for the water bending mode in solids, which is usually between 1600 and $1640 \mathrm{~cm}^{-1}$. According to the ab-initio calculations of M. Falk ${ }^{58}$ a decrease of the angular force constant may occur for very asymmetric H-O-H...F bent configurations, with equilibrium parameters not far from ours. The band at $1578 \mathrm{~cm}^{-1}$ presents a shoulder at $1660 \mathrm{~cm}^{-1}$. As mentioned, the shift of the bending mode to higher wave numbers can be ascribed to the occurrence of hydrogen bonds. ${ }^{59}$

Due to the charge difference between fluorine and oxygen anions, the force constants involving $\mathrm{M}^{-\mathrm{F}^{-}}$and $\mathrm{M}-\mathrm{O}^{2-}$ bonds (where $\mathrm{M}=\mathrm{Na}$ or $\mathrm{Ni}$ ) are expected to be quite different, then, vibrations arising from $\mathrm{F}^{-}$and $\mathrm{O}^{2-}$ are not expected to mix as in a one-mode behaviour. The bands in the $700-1000 \mathrm{~cm}^{-1}$ interval $\left(976,850\right.$ and $\left.702 \mathrm{~cm}^{-1}\right)$ are assigned to the deformation of the $\mathrm{M}-\mathrm{O}-\mathrm{H}(\mathrm{M}=\mathrm{Na}, \mathrm{Ni})$ bonds as well as to the rocking of the $\mathrm{O}-\mathrm{H}$ species. Absorptions between 500 and $350 \mathrm{~cm}^{-1}$ are attributed to the stretching of Ni-O/F bonds. We identify the $v(\mathrm{Ni}-\mathrm{F})$ and $v(\mathrm{Ni}-\mathrm{O})$ modes with the bands appearing at $407 \mathrm{~cm}^{-1}$ and $363 \mathrm{~cm}^{-1}$, respectively. Since we have concluded that protons are more strongly bonded to $\mathrm{O}$ than to $\mathrm{F}$, their effect on the Ni-F bond is expected to be weaker. The assignment of the band at $407 \mathrm{~cm}^{-1}$ to $v(\mathrm{Ni}-\mathrm{F})$ is supported by the finding of a mode at $450 \mathrm{~cm}^{-1}$ in hydrated $\mathrm{MNiF}_{3} \cdot \mathrm{H}_{2} \mathrm{O}$, where $v(\mathrm{Ni}-\mathrm{O})$ modes are absent because the lattice water is not coordinated to nickel. ${ }^{60}$

The $\mathrm{NaNi}(\mathrm{XH})_{6}$ sample annealed at $250^{\circ} \mathrm{C}$ (Figure 13b) exhibits a clearly different and much simpler IR spectrum. TG experiments revealed that thermal treatment at this temperature produced the loss of three water molecules. Accordingly, all vibrational modes ascribed to proton species are absent in the dehydrated sample. 


\section{Conclusions}

A new sodium nickel fluoride hydrate with composition $\mathrm{NaNiF}_{3} \cdot 3 \mathrm{H}_{2} \mathrm{O}$ has been prepared by a precipitation route from aqueous solution that differs from $\mathrm{NaMF}_{3}$ perovskites obtained with $\mathrm{M}=\mathrm{Mn}, \mathrm{Co}$ or $\mathrm{Zn}$. In $\mathrm{NaNiF}_{3} \cdot 3 \mathrm{H}_{2} \mathrm{O}$, a $\mathrm{ReO}_{3}$-type cubic $2 a \mathrm{x}$ $2 a$ x $2 a$ supercell ( $a$ being the simple $\mathrm{ReO}_{3}$ axis) was detected, in which octahedral $\mathrm{Na}$ and $\mathrm{Ni}$ are ordered in alternate contiguous $2 b$ and $2 c$ octahedral sites, but $\mathrm{O}$ and $\mathrm{F}$ anions are randomly distributed in $24 h$ sites (SG $P n-3$ ). This finding agrees with results reported in most transition metal oxyfluorides, that exhibit a random distribution in anion sites. ${ }^{49,50}$ The structural model deduced for $\mathrm{NaNiF}_{3} \cdot 3 \mathrm{H}_{2} \mathrm{O}$ is similar to that of $\mathrm{In}(\mathrm{OH})_{3}$, suggesting that protons are bonded to one mixed $\mathrm{O} / \mathrm{F}$ anion. The similarity becomes clearer if we write the formula as $\mathrm{NaNi}(\mathrm{XH})_{6}(\mathrm{X}=\mathrm{O}, \mathrm{F})$.

To investigate $\mathrm{O} / \mathrm{F}$ distribution at a local scale, IR/Raman and NMR spectroscopy have been used.The interpretation of spectroscopic results is based on the assumption that the basic structural units concerning anion and proton bonding are the anion squares connecting adjacent octahedra. Then, the different components of F-NMR spectra are assigned to F-F-F, O-F-F and O-F-O associations at the corners of these squares. The comparison between the relative intensities and the statistically calculated probability of occurrence of the different anion arrangements yields that an alternating, ordered disposition of $\mathrm{F}$ and $\mathrm{O}$ anions is highly disfavoured, thus supporting the hypothesis of a disordered anion distribution.

Regarding vibrational spectroscopy, the preferential association of protons to oxygen atoms when these are located near F ions was confirmed. This peculiarity, not 
found in compounds with a single type of anion such as $\operatorname{In}(\mathrm{OH})_{3}$, results in a nonnegligible probability of occurrence of two proton, water-like associations. Water-like entities are also detected in ${ }^{1} \mathrm{H}$ MAS-NMR spectra. However, the small intensity of the band at $5 \mathrm{ppm}$ attributed to water suggests that $\mathrm{NaNiF}_{3} \cdot 3 \mathrm{H}_{2} \mathrm{O}$ formulation is not favoured.

\title{
Acknowledgements
}

We thank Ministerio de Ciencia e Innovación and Comunidad de Madrid for funding the projects MAT2010-19837-C06 and P2009/PPQ-1626 respectively. Financial support from Universidad CEU San Pablo is also acknowledged.

Supporting Information Available: An X-ray crystallographic file in CIF format including crystallographic details and atomic coordinates. Figure S1 with Rietveld analysis of the XRD patterns of $\mathrm{NaNiF}_{3} \cdot 3 \mathrm{H}_{2} \mathrm{O}$. This material is available free of charge via the Internet at http://pubs.acs.org.

\author{
Author Information \\ Corresponding Author \\ *Tel: +34-913724735. Fax: +34-913510475. E-mail: akuhn@ceu.es
}




\begin{tabular}{|c|c|c|}
\hline Chemical formula & \multicolumn{2}{|c|}{$\mathrm{NaNiF}_{3} \cdot 3 \mathrm{H}_{2} \mathrm{O}$} \\
\hline Diffraction type & X-ray powder & Neutron powder \\
\hline Temperature & \multicolumn{2}{|c|}{$\mathrm{T}=298 \mathrm{~K}$} \\
\hline Diffractometer & Bruker D8 & SPODI at MLZ \\
\hline Radiation & $\lambda=1.54056 \AA\left(\mathrm{Cu}-\mathrm{K}_{\alpha 1}\right)$ & $\lambda=1.54811 \AA$ \\
\hline $2 \theta$ angular range & $10-100^{\circ}$ & $18-150^{\circ}$ \\
\hline Step, time per step & $0.014643,12 \mathrm{~s}$ & 0.05, monitor $=250000$ \\
\hline Crystal system & \multicolumn{2}{|c|}{ Cubic } \\
\hline Space group & \multicolumn{2}{|c|}{$P n-3$ (\# 201) } \\
\hline Lattice parameter & \multicolumn{2}{|c|}{$a=7.92133(6) \AA$} \\
\hline Number of reflections & 47 & 177 \\
\hline Refined structural parameters & 6 & 10 \\
\hline Refined profile parameters & 8 & 8 \\
\hline Number of atoms & 3 & 5 \\
\hline Reliability factors & $\begin{array}{l}R_{\mathrm{p}}=0.087 \\
R_{\mathrm{wp}}=0.116 \\
R_{\text {Bragg }}=0.052 \\
R_{\text {exp }}=0.067 \\
\chi^{2}=2.99\end{array}$ & $\begin{array}{l}R_{\mathrm{p}}=0.087 \\
R_{\mathrm{wp}}=0.086 \\
R_{\text {Bragg }}=0.042 \\
R_{\text {exp }}=0.048 \\
\chi^{2}=3.32\end{array}$ \\
\hline
\end{tabular}

Table 1. Experimental conditions and refined parameters of the co-refined X-ray and neutron diffraction data of $\mathrm{NaNiF}_{3} \cdot 3 \mathrm{H}_{2} \mathrm{O}$ in $P n-3$.

Table 2. Atomic positions, isotropic thermal displacement and occupancies determined by simultaneous fitting of PXRD and NPD data for $\mathrm{NaNiF}_{3} \cdot 3 \mathrm{H}_{2} \mathrm{O}$ (S.G. $P n-3$ )

\begin{tabular}{lllllll}
\hline Atom & Site & $\boldsymbol{x}$ & $\boldsymbol{y}$ & $\boldsymbol{z}$ & Occ. & U*100 \\
\hline $\mathbf{N a}$ & $4 \mathrm{c}$ & 0.5 & 0.5 & 0.5 & 1.0 & $0.92(3)$ \\
$\mathbf{N i}$ & $4 \mathrm{~b}$ & 0 & 0 & 0 & 1.0 & $1.1(1)$ \\
$\mathbf{O} / \mathbf{F}$ & $24 \mathrm{~h}$ & $0.0900(1)$ & $0.5753(2)$ & $0.2722(1)$ & 1.0 & $1.2(1)$ \\
$\mathbf{H 1}$ & $24 \mathrm{~h}$ & 0.75 & $0.7224(5)$ & $0.0676(5)$ & 0.5 & $1.4(2)$ \\
$\mathbf{H 2}$ & $24 \mathrm{~h}$ & $0.7058(4)$ & 0.25 & $0.0766(5)$ & 0.5 & $1.4(2)$
\end{tabular}

Bond valence sums: $\mathrm{Na}(4 \mathrm{c})=1.18 ; \mathrm{Ni}(4 \mathrm{~b})=2.02$ 
Table 3. Bond distances $(\AA)$ and angles $\left({ }^{\circ}\right)$ with standard deviations in $\mathrm{NaNiF}_{3} \cdot 3 \mathrm{H}_{2} \mathrm{O}$ determined from X-ray and neutron data.

\begin{tabular}{|c|c|c|c|}
\hline Distances $(\AA)$ & & Angles $\left(^{\circ}\right)$ & \\
\hline $\mathrm{Na}-\mathrm{O} / \mathrm{F}$ & $2.348(2) \times 6$ & $\mathrm{O} / \mathrm{F}-\mathrm{Na}-\mathrm{O} / \mathrm{F}$ & $88.2(1)$ \\
\hline $\mathrm{O} / \mathrm{F}-\mathrm{O} / \mathrm{F}$ (octahedron edge) & $3.267(2) \times 6$ & & $91.8(1)$ \\
\hline & $3.372(2) \times 6$ & $\mathrm{Na}-\mathrm{O} / \mathrm{F}-\mathrm{H} 1$ & $97.6(2)$ \\
\hline & & $\mathrm{Na}-\mathrm{O} / \mathrm{F}-\mathrm{H} 2$ & $93.8(2)$ \\
\hline $\mathrm{Ni}-\mathrm{O} / \mathrm{F}$ & $2.029(2) \times 6$ & $\mathrm{O} / \mathrm{F}-\mathrm{Ni}-\mathrm{O} / \mathrm{F}$ & $87.0(1)$ \\
\hline & & & $93.0(1)$ \\
\hline $\mathrm{O} / \mathrm{F}-\mathrm{O} / \mathrm{F}$ (octahedron edge) & $2.794(2) \times 6$ & $\mathrm{Ni}-\mathrm{O} / \mathrm{F}-\mathrm{H} 1$ & $118.4(2)$ \\
\hline & $2.944(2) \times 6$ & $\mathrm{Ni}-\mathrm{O} / \mathrm{F}-\mathrm{H} 2$ & $113.7(2)$ \\
\hline $\mathrm{Na}-\mathrm{Ni}$ & $3.9598(1)$ & $\mathrm{Na}-\mathrm{O} / \mathrm{F}-\mathrm{Ni}$ & $129.4(1)$ \\
\hline $\mathrm{O} / \mathrm{F}-\mathrm{O} / \mathrm{F}$ (square units) & $2.559(3) \times 2$ & & \\
\hline & $2.789(3) \times 2$ & & \\
\hline $\mathrm{O} / \mathrm{F}-\mathrm{H} 1$ & $1.065(5)$ & $\mathrm{O} / \mathrm{F} \cdots \mathrm{H} 1-\mathrm{O} / \mathrm{F}$ & $173.7(4)$ \\
\hline $\mathrm{O} / \mathrm{F}-\mathrm{H} 2$ & $1.054(4)$ & $\mathrm{O} / \mathrm{F} \cdot \cdot \mathrm{H} 2-\mathrm{O} / \mathrm{F}$ & $170.0(3)$ \\
\hline $\mathrm{O} / \mathrm{F} \cdots \mathrm{H} 1$ & $1.497(5)$ & $\mathrm{H} 1-\mathrm{O} / \mathrm{F}-\mathrm{H} 2$ & $97.3(3)$ \\
\hline $\mathrm{O} / \mathrm{F} \cdots \mathrm{H} 2$ & $1.746(4)$ & & \\
\hline
\end{tabular}


Table 4. $\mathrm{ReO}_{3}$-hettotypes and deduced tilting angles $\varphi$ about $\langle 111\rangle$

\begin{tabular}{|c|c|c|c|c|c|}
\hline Compound & Lattice parameter a / $\AA$ & S.G. & $\mathrm{M}-\mathrm{X}-\mathrm{M}$ angle $\theta /^{\mathrm{o}}$ & Tilting angle $\varphi_{<111>} /^{\circ}$ & ref \\
\hline $\mathrm{ReO}_{3}$ & $3.7054(1)$ & Pm-3m & 180.0 & - & 38 \\
\hline $\mathrm{hp}-\mathrm{ReO}_{3}$ & $7.4456(2)-7.1618(7)$ & Im-3 & $166.0-146.4$ & $8.6-20.6$ & $33^{a}$ \\
\hline $\mathrm{NbO}_{2}(\mathrm{OH})$ & $7.645(2)$ & Im-3 & 148.4 & 19.4 & 32 \\
\hline $\mathrm{Sc}(\mathrm{OH})_{3}$ & $7.882(5)$ & $\operatorname{Im}-3$ & 140.9 & 24.0 & 21 \\
\hline $\mathrm{In}(\mathrm{OH})_{3}$ & $7.9743(6)$ & Im-3 & 134.6 & 27.9 & 23 \\
\hline $\begin{array}{l}\mathrm{CoAs}_{3} \\
\text { (skutterudite) }\end{array}$ & $8.2055(3)$ & $\operatorname{Im}-3$ & 123.5 & 33.0 & 39 \\
\hline $\mathrm{NaSbF}_{6}$ & $8.184(5)$ & Fm-3m & 180.0 & - & 40 \\
\hline $\begin{array}{l}\mathrm{CaSn}(\mathrm{OH})_{6} \\
\text { (burtite) }\end{array}$ & 8.15 & Pn-3 & 135.7 & 27.2 & $34,35^{b}$ \\
\hline $\begin{array}{l}\mathrm{MSn}(\mathrm{OH})_{6} \\
\mathrm{M}=\mathrm{Mn}, \mathrm{Zn}\end{array}$ & $7.8744(5), 7.80(1)$ & Pn-3 & 136.7 & 26.6 & $34-36$ \\
\hline $\begin{array}{l}\mathrm{NaNiF}_{3} \cdot 3 \mathrm{H}_{2} \mathrm{O} \\
=\mathrm{NaNi}(\mathrm{XH})_{6}\end{array}$ & $7.91968(4)$ & Pn-3 & 129.4 & 31.1 & $\mathrm{c}$ \\
\hline $\mathrm{NbO}_{2} \mathrm{~F}$ & $3.899(2)$ & Pm-3m & 180.0 & - & 41 \\
\hline $\mathrm{hp}-\mathrm{NbO}_{2} \mathrm{~F}$ & $\begin{array}{l}5.519-4.823 \\
\alpha=60.002-63.219^{\circ}\end{array}$ & $\mathrm{R}-3 \mathrm{c}$ & $155.8-140.9$ & $14.8-24.0$ & $42^{\mathrm{d}, \mathrm{e}}$ \\
\hline $\mathrm{FeF}_{3}$ & $\begin{array}{l}5.362(1) \\
\alpha=57.94(2)\end{array}$ & $\mathrm{R}-3 \mathrm{c}$ & 152.1 & 17.1 & $43^{d}$ \\
\hline
\end{tabular}

${ }^{\mathrm{a}} \theta=166.0^{\circ}$ at $1270 \mathrm{MPa} ; \theta=146.4^{\circ}$ at $8010 \mathrm{MPa}$.

b at $4 \mathrm{~K}$

${ }^{\mathrm{c}}$ from this work

${ }^{\mathrm{d}}$ titlting scheme is $a^{-} a^{-} a^{-}$

${ }^{\mathrm{e}} \theta=155.8^{\circ}$ at $1380 \mathrm{MPa} ; \theta=140.9^{\circ}$ at $10500 \mathrm{MPa}$ 


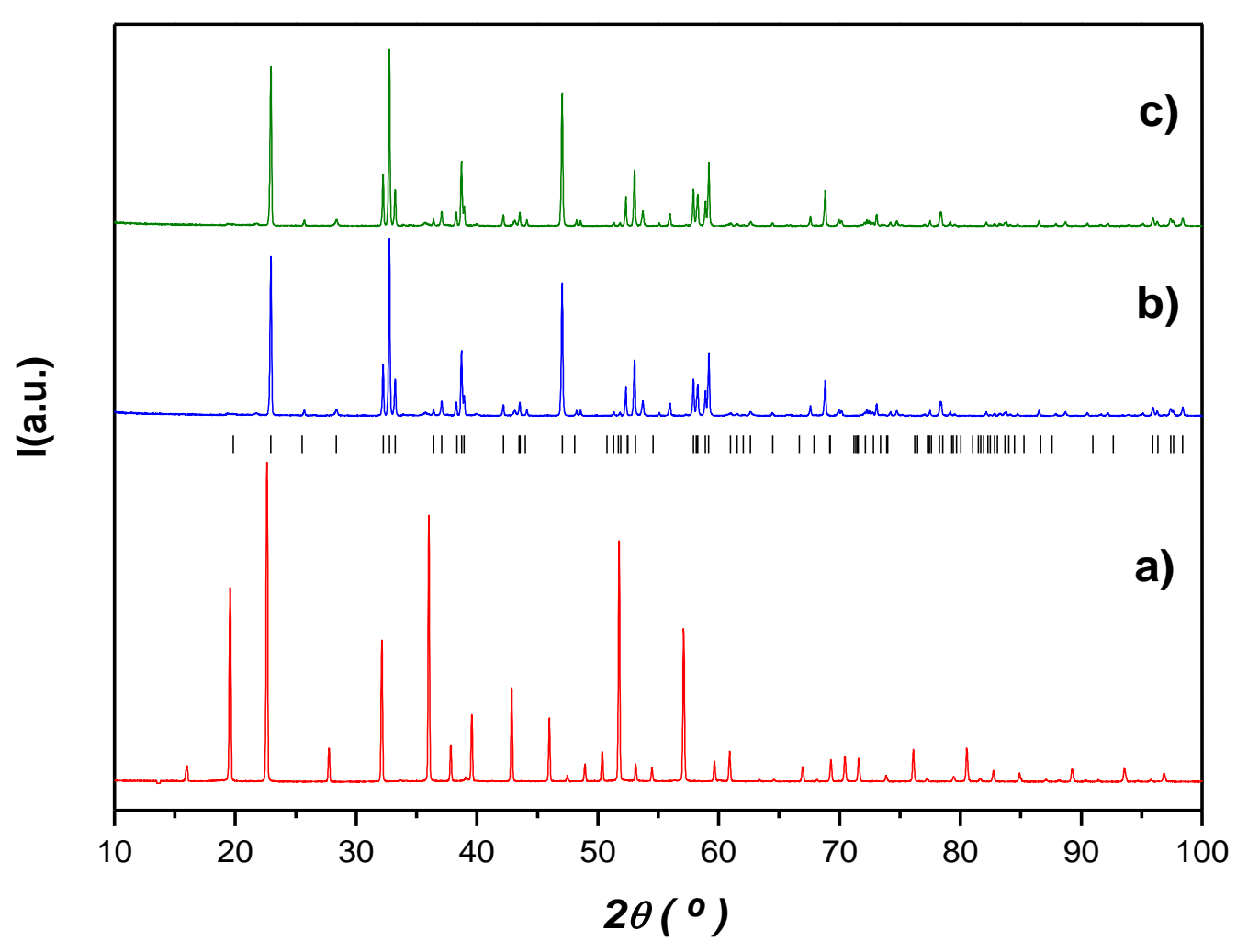

Figure 1 


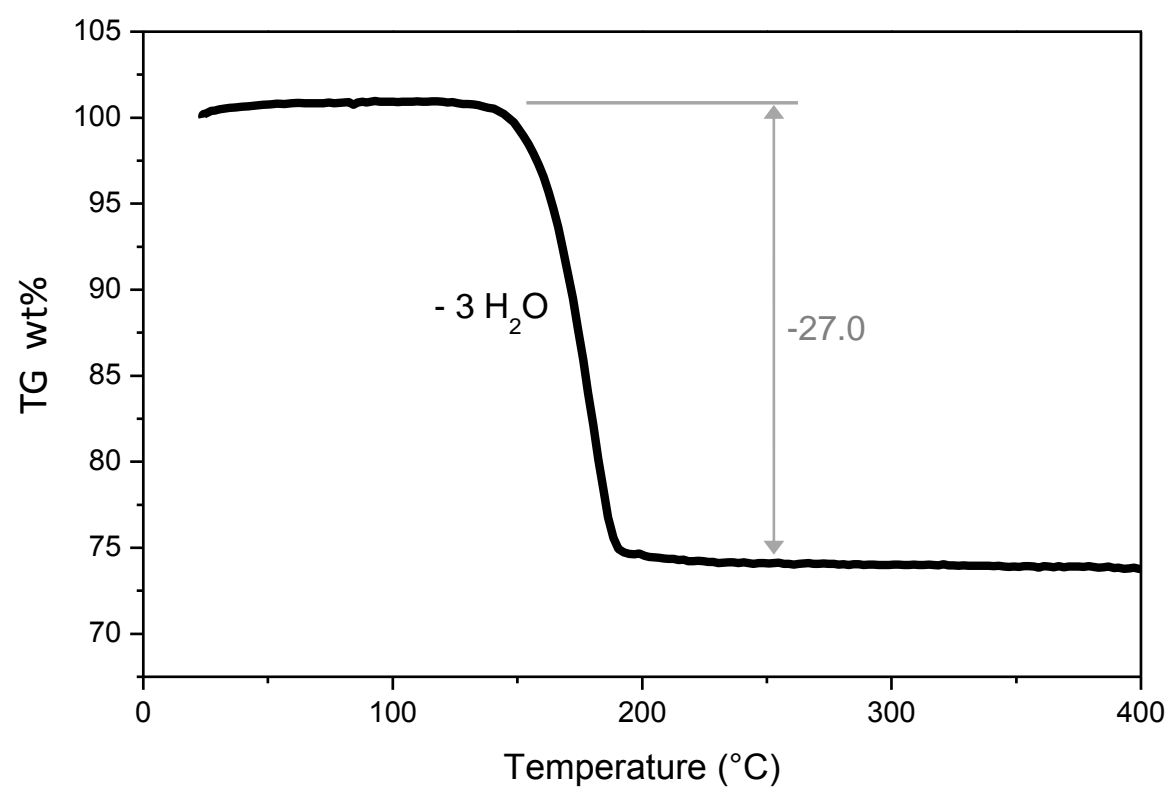

Figure 2 


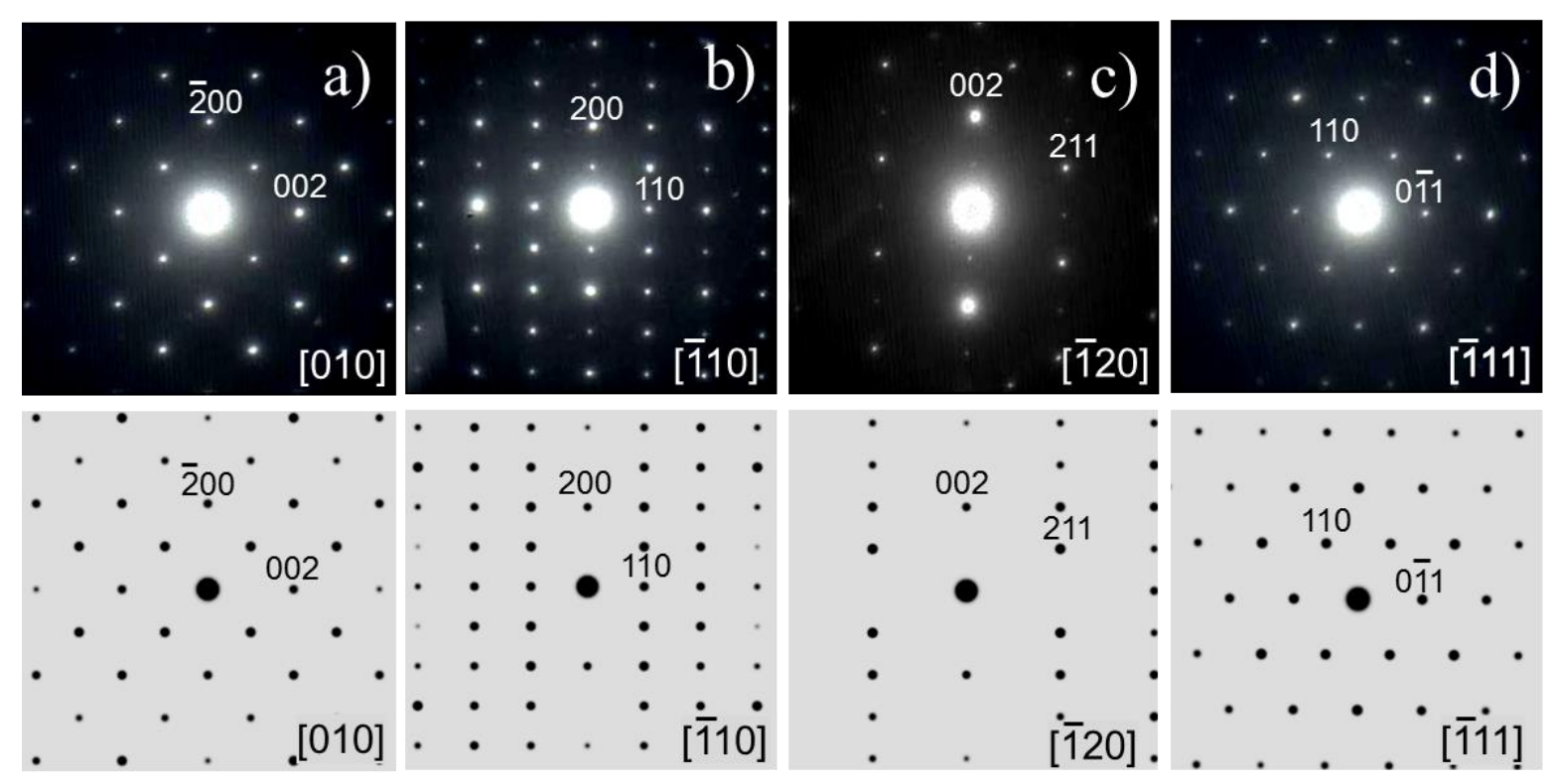

Figure 3 


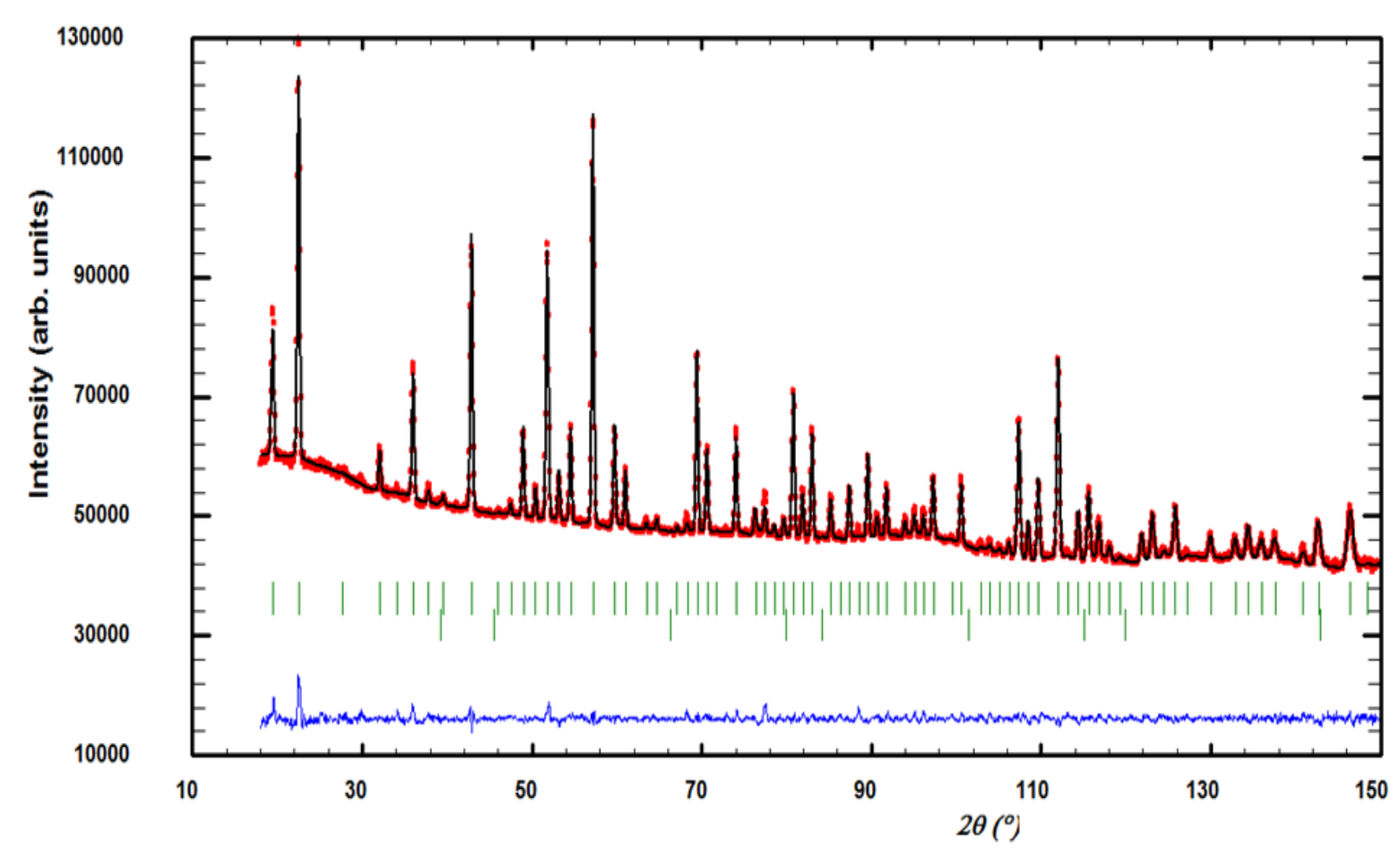

Figure 4 

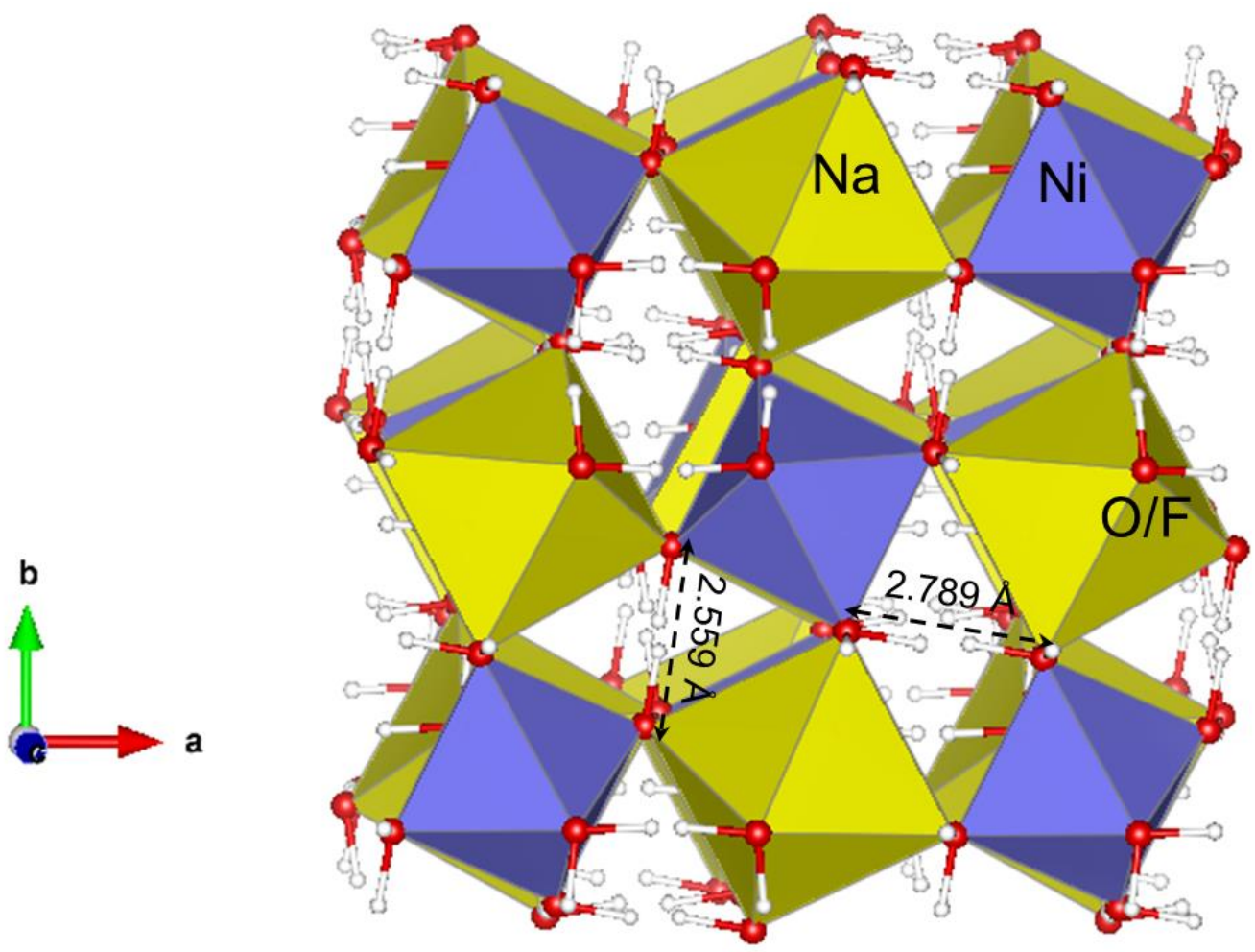

Figure 5 


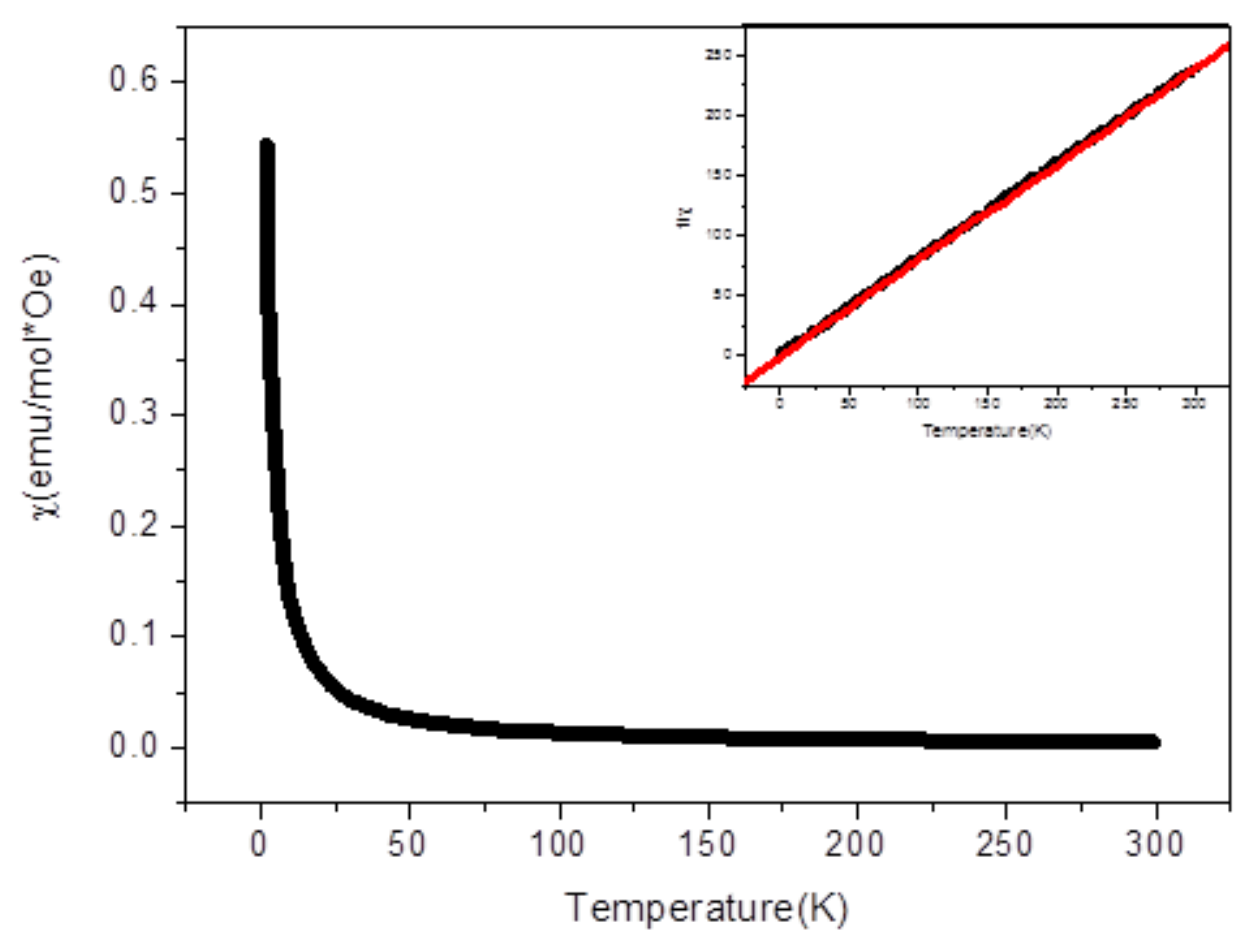

Figure 6 


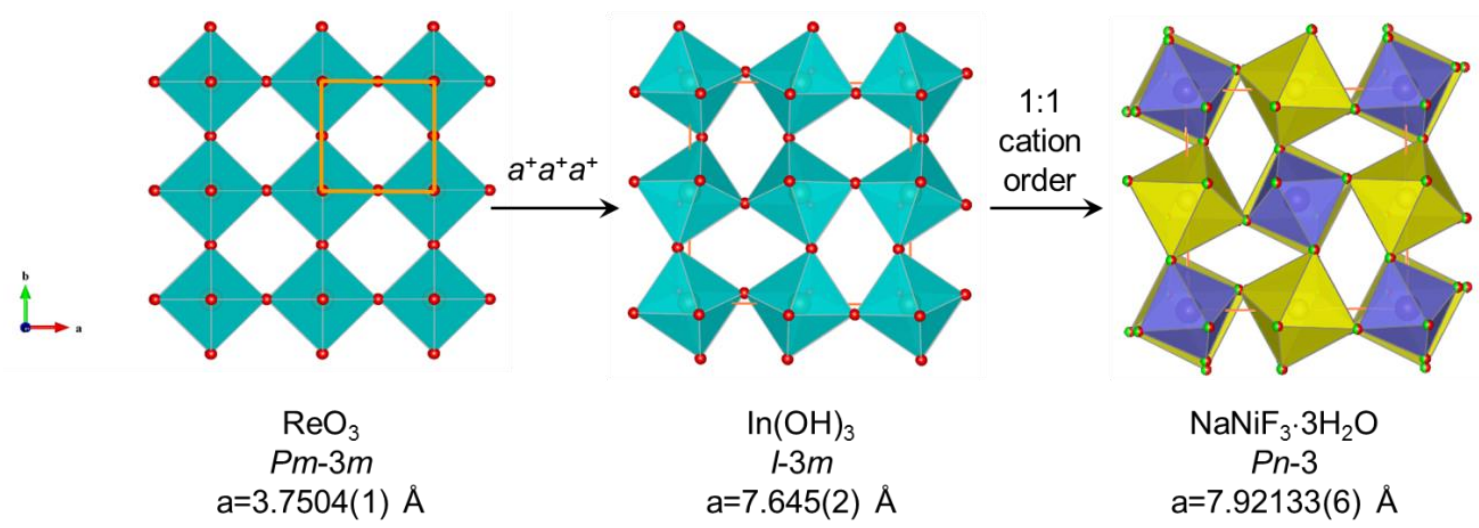

Figure 7 


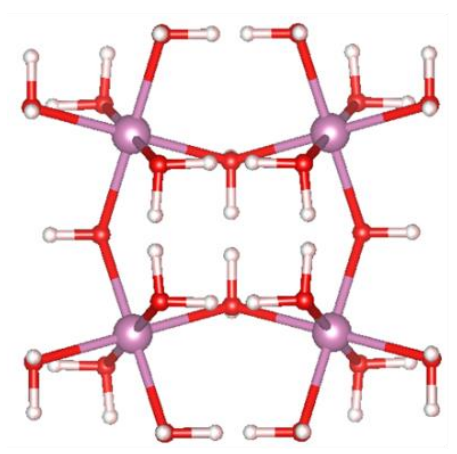

(a)

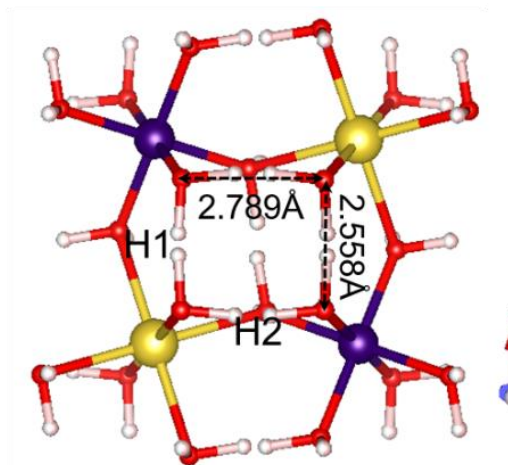

(b)

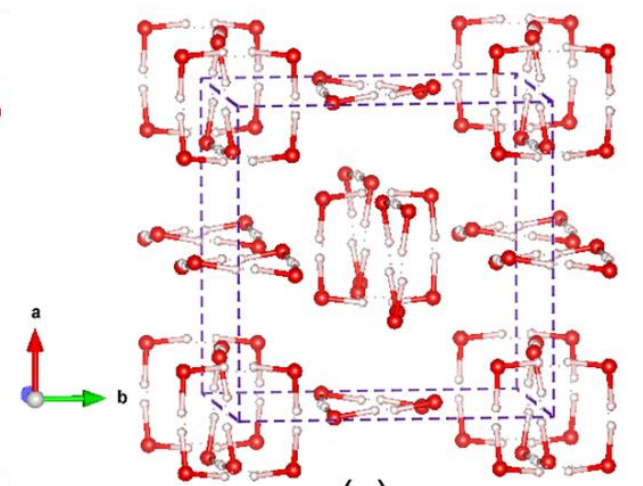

(c)

\section{Figure 8}




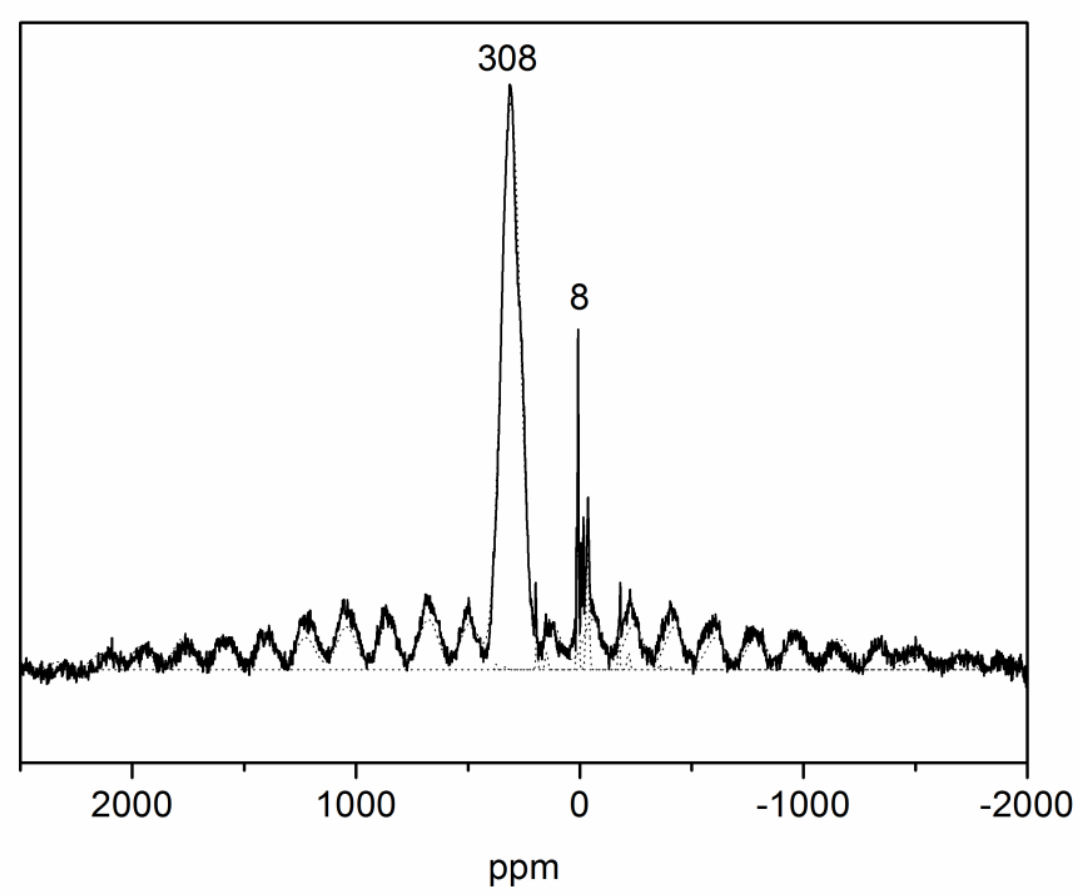

Figure 9 


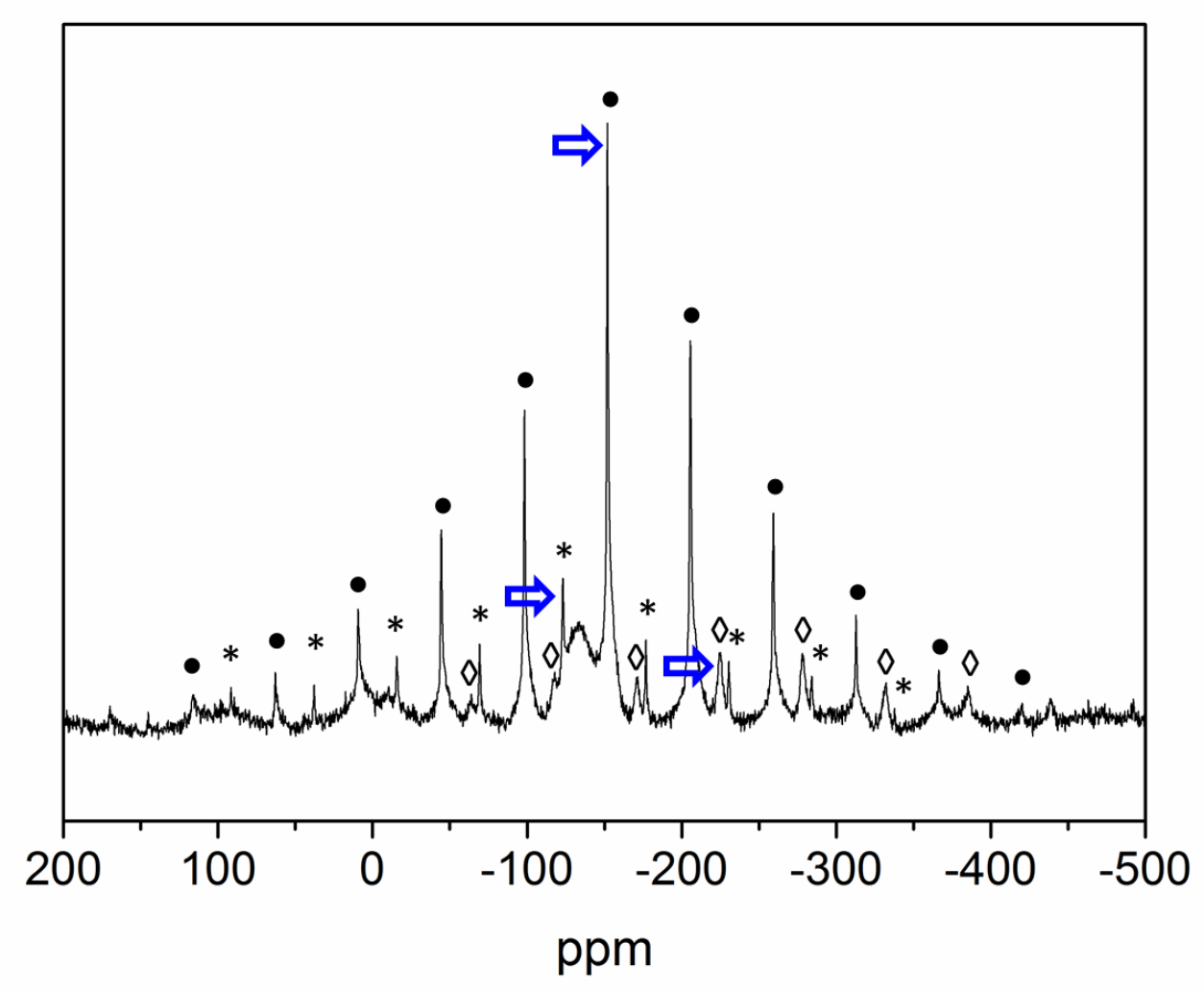

Figure 10 


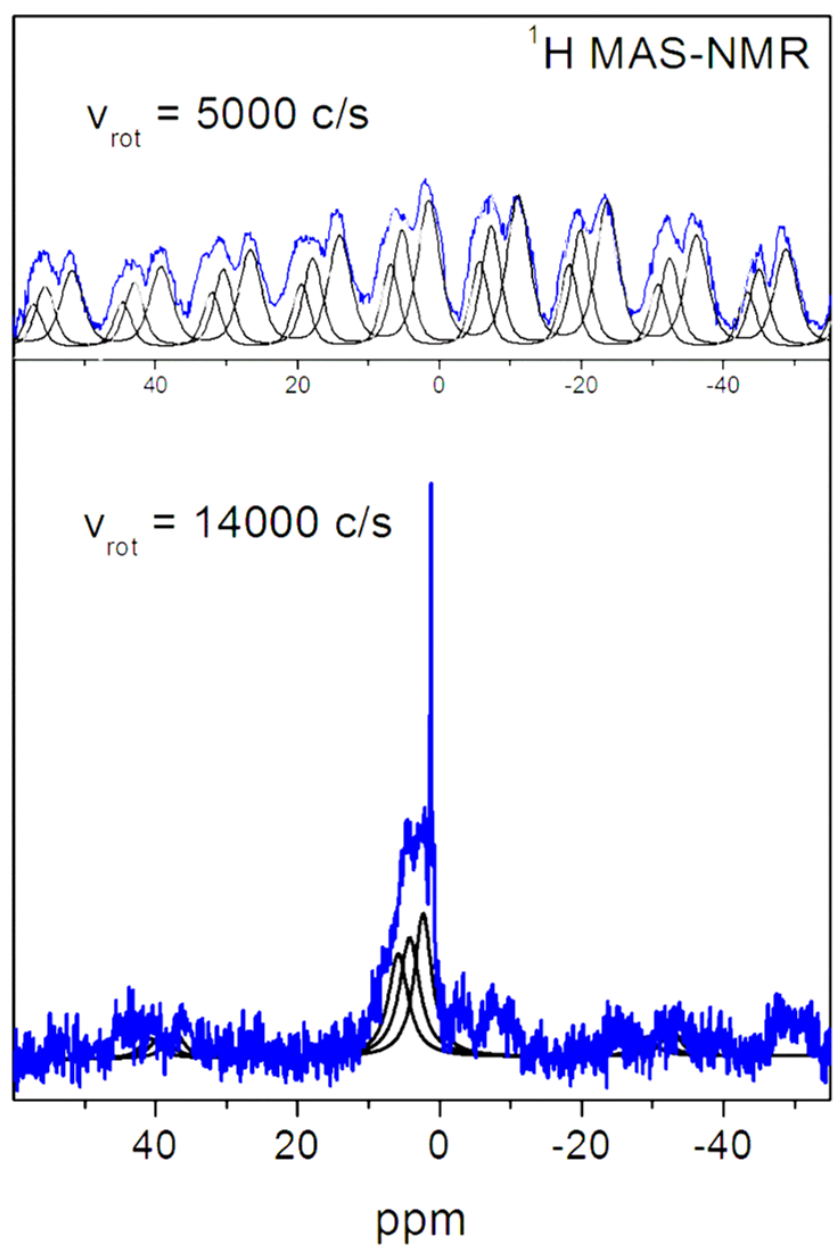

Figure 11 


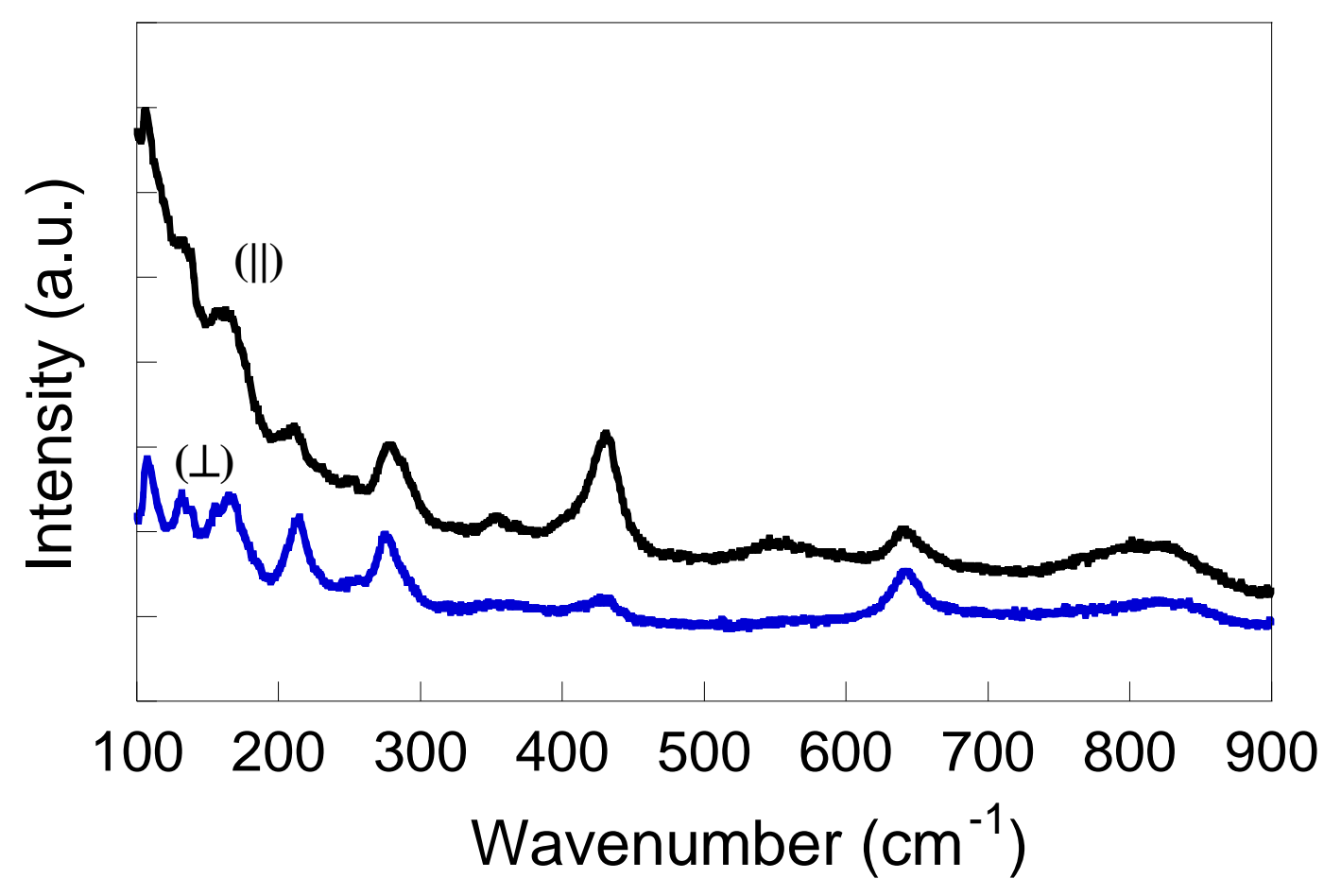

Figure 12 


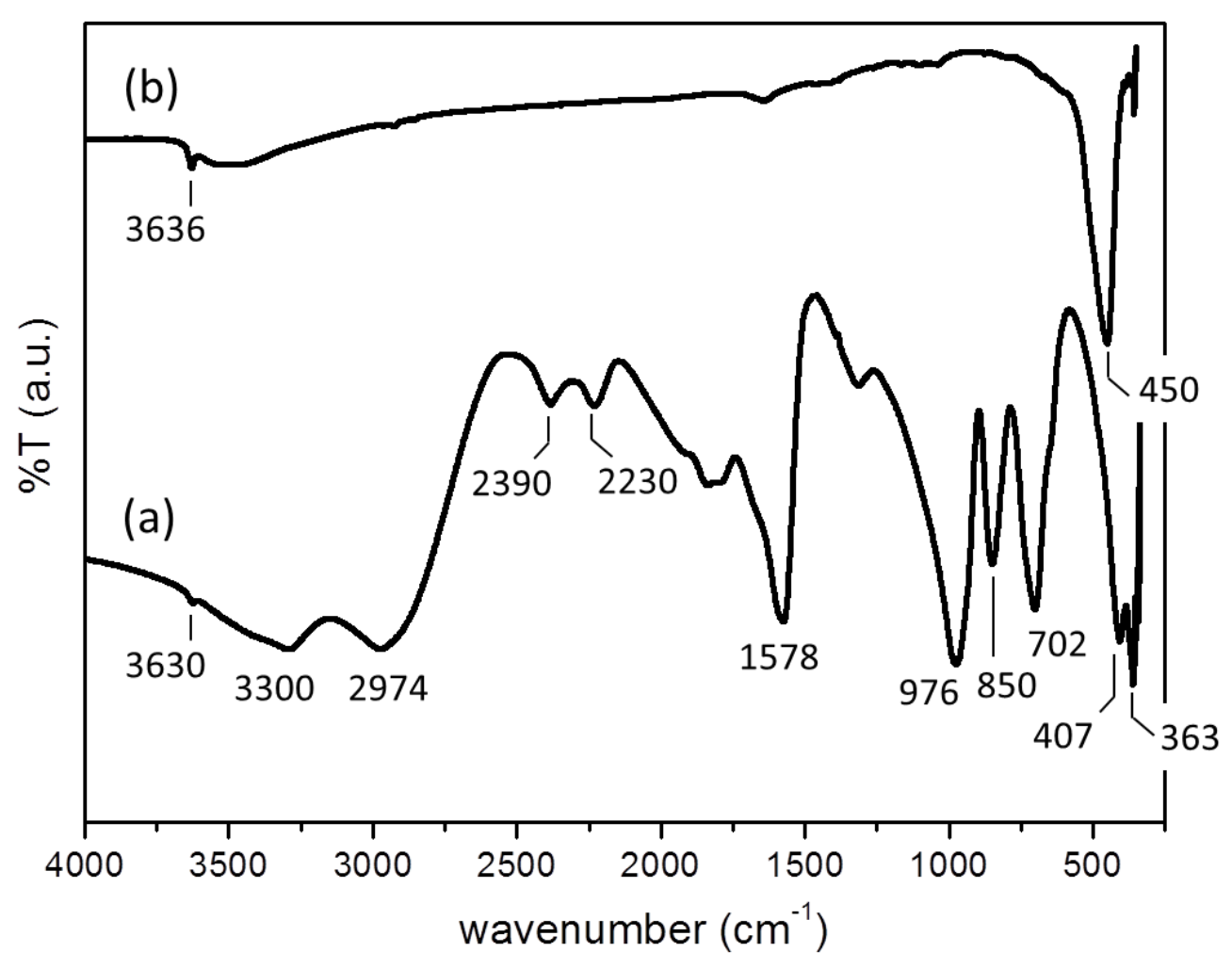

Figure 13 


\section{Figure Captions}

Figure 1: Powder X-ray diffraction profiles corresponding to nominal $\mathrm{NaNiF}_{3}$ obtained by precipitation (a), together with that of $\mathrm{NaCoF}_{3}$ obtained by precipitation (b) and $\mathrm{NaNiF}_{3}$ using the ceramic route (c). Diffraction patterns of $\mathrm{NaCoF}_{3}$ (b) and $\mathrm{NaNiF}_{3}$ (c) are compatible with those of the perovskite structure, space group Pbnm.

Figure 2: Variation of weight of $\mathrm{NaNiF}_{3} \cdot 3 \mathrm{H}_{2} \mathrm{O}$ compound with temperature under flowing nitrogen. The three hydration water molecules are lost in the $150-200^{\circ} \mathrm{C}$ range.

Figure 3: Selected area electron diffraction (SAED) images obtained for $\mathrm{NaNiF}_{3} \cdot 3 \mathrm{H}_{2} \mathrm{O}$ compound, indexed with a cubic parameter of $a \sim 8 \AA$ along several zone axes: [010] (a). [-110] (b), [-120] (c) and [-111] (d). The corresponding calculated patterns are given below.

Figure 4: NPD pattern of $\mathrm{NaNiF}_{3} \cdot 3 \mathrm{H}_{2} \mathrm{O}$ modelled with a cubic $(P n-3) 2 a \times 2 a \times 2 a$ supercell. The solid (black) line corresponds to the model fitted to the data (red circles) and the (blue) line beneath corresponds to the difference between them. Vertical (green) bars indicate the allowed Bragg reflections. In refinements a small amount of the secondary $\mathrm{NaF}$ phase was considered (lower vertical bars).

Figure 5: Structure of $\mathrm{NaNiF}_{3} \cdot 3 \mathrm{H}_{2} \mathrm{O} . \mathrm{Na}(\mathrm{O} / \mathrm{F})_{6}$ (large yellow octahedra), $\mathrm{Ni}(\mathrm{O} / \mathrm{F})_{6}$ (small blue octahedra), F/O atoms (red big spheres) and $\mathrm{H}$ atoms (white small spheres). 
Figure 6: Magnetic molar susceptibility of $\mathrm{NaNiF}_{3} \cdot 3 \mathrm{H}_{2} \mathrm{O}$ as function of temperature. The inset shows the temperature dependence of the inverse magnetic susceptibility. The (red) solid line illustrates the fit to Curie's law.

Figure 7: Relationship between the primitive cubic $\mathrm{ReO}_{3}$ and the $2 a \times 2 a \times 2 a$ cubic supercells produced by $a^{+} a^{+} a^{+}$octahedral tilting without and with 1:1 cation ordering, respectively (after $\left.{ }^{9,19}\right)$.

Figure 8: Projection down the [001] direction of four corner-sharing $\mathrm{Na}(\mathrm{O} / \mathrm{F})_{6}$ and $\mathrm{Ni}(\mathrm{O} / \mathrm{F})_{6}$ octahedra in $\mathrm{NaNi}(\mathrm{XH})_{6}(\mathrm{X}=\mathrm{O}, \mathrm{F})(\mathrm{b})$ together with the positions of hydrogen atoms. The corresponding projection is displayed for $\operatorname{In}(\mathrm{OH})_{3}$ for comparison (a). Arrangement of the $\mathrm{H}$ bonding corrugated square motifs in the unit cell (c).

Figure 9: ${ }^{23} \mathrm{Na}$ MAS-NMR spectrum of $\mathrm{NaNi}(\mathrm{XH})_{6}$. The broad signal at $308 \mathrm{ppm}$ with the corresponding spinning sidebands have been ascribed to $\mathrm{Na}$ in octahedra of this phase. The narrow sharp signal at $8 \mathrm{ppm}$ corresponds to $\mathrm{NaF}$ as minor secondary phase.

Figure 10: ${ }^{19} \mathrm{~F}$ MAS-NMR spectrum of $\mathrm{NaNi}(\mathrm{XH})_{6}$. (Blue) arrows point the three different bands centred at $-123,-151$ and $-221 \mathrm{ppm} .\left(^{*}\right),(\bullet)$ and $(\diamond)$ symbols denote spinning side bands of these three components.

Figure 11: ${ }^{1} \mathrm{H}$ MAS-NMR spectrum of $\mathrm{NaNi}(\mathrm{XH})_{6}$. The increment of the spinning rate allowed a better estimation of intensity of components. 
Figure 12: Raman spectra of a $\mathrm{NaNi}(\mathrm{XH})_{6}$ single crystal with incoming and outgoing electric fields either parallel $(\|)$ or perpendicular $(\perp)$ to each other.

Figure 13: FT-IR spectrum of $\mathrm{NaNi}(\mathrm{XH})_{6}$ (a) and after annealing at $250^{\circ} \mathrm{C}$ (b). 


\section{References}

(1) Rüdorff W., Kändler J. Naturwissenschaften 1957, 418.

(2) Knox K., Acta Crystallogr. 1961, 14, 583-585.

(3) Rüdorf W., Lincke G., Babel D., Z. Anorg. Allg. Chem. 1963, 320, 150-170.

(4) Petrov M.P., Soviet Physics Solid State 1965, 7, 1348.

(5) Pisarev R.V., Soviet Physics Solid State 1965, 7, 1114.

(6) Tutov A.G., Syrnikov P.P., Acta Crystallogr. 1966, S 21, A272.

(7) Rüdorf W., Kändler J., Babel D., Z. Anorg. Allg. Chem. 1962, 317, 261-352.

(8) Lutgert B., Babel D., Z. Anorg. Allg. Chem. 1992, 616, 133-140.

(9) Glazer A.M., Acta Crystallogr. A 1975, 31, 756-789.

(10) Gocheva I.D., Nishijima M., Doi T., Okada S., Yamaki J., Nishida T., J. Power Sources 2009, 187, 247-252.

(11) Kitajou A, Komatsu H, Chihara K, Gocheva, ID, Okada, S., J. Power Sources 2012, 198, 389-392.

(12) Yamada Y, Doi T, Tanaka I, Okada, S., Yamaki, J., J. Power Sources 2011, 196, $4837-4841$.

(13) Gonzalo E., Kuhn A., Garcia-Alvarado F. (in preparation)

(14) Altomare A, Camalli M., Cuocci C., Moliterni A., Rizzi R., J. Appl. Cryst. 2009, $42,1197-1202$.

(15) Rodriguez-Carvajal J., Physica B: Condensed Matter 1993, 192, 55-69.

(16) Roisnel T., Rodríguez Carvajal J., EPDIC 7: European powder diffraction, PTS1, 2 2000, 378, 118-123.

(17) Sears V.F., Neutron News 1992, 3, 29-37.

(18) Altomare A., Campi G., Cuocci C., Eriksson L., Giacovazzo C., Moliterni A., Rizzi R., Werner P.-E., J. Appl. Cryst. 2009, 42, 768-775. 
(19) Woodward P.M., Acta Crystallogr. B 1997, 53, 32-43.

(20) Woodward P.M., Acta Crystallogr. B 1997, 53, 44-66.

(21) Schubert K.. Seitz A., Z. Anorg. Allg. Chem. 1948, 256, 226-238.

(22) Christensen A.N., Acta Chem. Scand. 1967, 21, 1046-1056.

(23) Mullica D.F., J. Inorg. Nucl. Chem. 1979, 41, 277-282.

(24) Shannon R.D., Acta Crystallogr. A 1976, 32, 751-767.

(25) Cairns, R.W., Ott, E., J. Amer. Chem. Soc. 1933, 55, 527-533.

(26) Babel D., Herdtweck E., Z. Anorg. Allg. Chem. 1982, 487, 75-84.

(27) Stehr H., Z. Kristallogr. 1967, 125, 332-359.

(28) Jansen M., Hoppe R., Z. Anorg. Allg. Chem. 1974, 408, 104-106.

(29) Bragg W.L., Nature 1920, 105, 646-648.

(30) Hawthorne F.C., Ferguson R.B., Can. Mineral. 1975, 13, 377-382.

(31) Bock O., Müller U., Z. Anorg. Allg. Chem. 2002, 628, 987-992.

(32) Fourquet J.E., Renou M.F., De Pape R., Teveneau H., Man P.P., Lucs O., Pannetier J., Solid State Ionics 1983, 9, 1011-1013.

(33) Jorgensen, J.E., Marshall, W.G., Smith, R.I., Olsen, J.S., Gerward, L., J. Appl. Cryst. 2004, 37, 857-861.

(34) Struntz H., Contag B., Acta Crystallogr. 1960, 13, 601-603.

(35) Cohen-Addad C., Bull. Soc. Fr. Mineral. Cristallogr. 1968, 91, 315-324.

(36) Basciano L.C., Peterson R.C., Roeder L., Swainson I., Can. Mineral. 1998, 36, 1203.

(37) O'Keefe M., Hyde B. G., Acta Crystallogr. 1977, B33, 3802-3813.

(38) Jorgensen, J.E., Jorgensen, D.J., Batlogg, B., Remeika, J.P., Axe, J.D., Physical Review 1986, B33, 4793-4798.

(39) Kjekshus, A., Rakke, T., Acta Chem. Scand. 1974, 28, 99-103. 
(40) Teufer, G., Acta Crystallogr. 1956, 9, 539-540.

(41) Pouchard, M., Torki, M.R., Demazeau, G., Hagenmuller, P., Comptes Rendus

Hebdomadaires des Seances de l'Academie des Sciences C 1971, 273, 1093-1096.

(42) Carlson, S., Larsson, A.K., Rohrer, F.E., Acta Crystallogr. 2000, B56, 189-196.

(43) Leblanc, M., Pannetier, J., Ferey, G., de Pape, R. Revue de Chim. Miner. 1985, 22, 107-114.

(44) Hepworth, M.A., Jack, K.H., Peacock, R.D., Westland, G.J., Acta Crystallogr. 1957, 10, 63-69.

(45) Hamilton W. C., Ann. Rev. Phys. Chem. 1962, 13, 19.

(46) Pedersen B., Acta Crystallogr. B 1974, 30, 289.

(47) Mackenzie K.J.D., Smith M.E., Multinuclear Solid-State NMR of Inorganic Materials; Pergamon: Oxford, 2002.

(48) Martin C.D., Chaudhuri S., Grey C.P., Parise J.B., Amer. Mineral. 2005, 90, 15221533.

(49) Brink F.J., Withers R.L., Thompson J.G., J. Solid State Chem. 2000, 155, 359-365.

(50) Brink F.J., Noren L., Withers, R.L., J. Solid State Chem. 2004, 177, 2177-2182.

(51) Nakamoto K., Infrared and raman Spectra of Inorganic and Coordination Compounds; Wiley: New York, 1986.

(52) Libowitzky E., Monatshefte für Chemie 1999, 130, 1047.

(53) Steiner T., Angew. Chem. Int. Ed. 2002, 41, 48.

(54) Mikenda W., Steinböck S., J. Mol. Struct. 1994, 326, 123-130.

(55) Panich A.M., Chem. Phys. 1995, 196, 511.

(56) Kawaguchi K., Hirota E., J. Chem. Phys. 1987, 87, 6838.

(57) Jiang G.J., Anderson G.R., J. Phys. Chem. 1973, 77, 1764.

(58) Falk M., Spectrochim. Acta 1986, 42A, 175. 
(59) Burneau A., J. Mol. Liq. 1990, 46, 99-127; Burneau A., J. Chim. Phys. et PhysicoChim. Biol. 1972, 69, 171.

(60) Chaudhuri M.K., Ghosh S.K., Hiese Z., Transition Metal Chem. 1985, 10, 321322. 


\section{For Table of Contents Only}

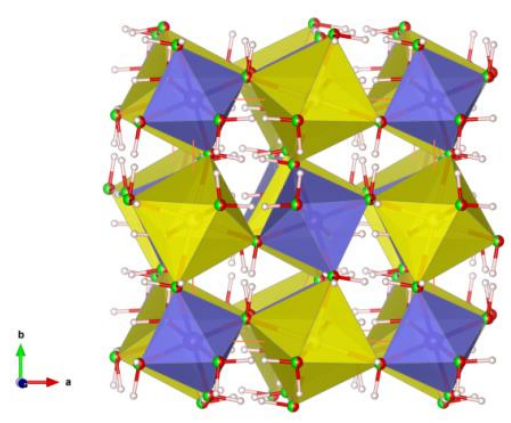

The structure of $\mathrm{NaNiF}_{3} \cdot 3 \mathrm{H}_{2} \mathrm{O}$ : the ordered cation link-up contrasts with anion disorder in a $\mathrm{ReO}_{3}$-type superstructure ruled by significant hydrogen bonding. 